\title{
Dortus.008.819
}

\section{Child Restraints}

ISSUE PAPER

\author{
U.S. DEPARTMENT OF TRANSPORIATION \\ National Highway Traffic Safety Administration \\ Trafflc Safefy Programs \\ Revised March 1980
}




\section{CHILD RESTRAINT USAGE}

\section{$\underline{\text { Issue }}$}

There is a need for increasing the protection of children in passsenger vehicles. In 1978, 670 children under the age of 5 and 1,160 children between the ages of 5 and 14 died as passengers in automobile accidents and tens of thousands more were injured. Efforts to gain State child restraint laws have, with one exception, been unsuccessful. Recent surveys have indicated that a vast majority (approximately 93 percent) of children less than ten years of age travel without any restraints at all.

\section{Discussion}

Children, because of their high center of gravity and delicate bone structure, are extremely susceptible to injury in automobile accidents. Further, children do not benefit as much from padding and other energy absorbing parts of the vehicle interior as adults do. If unrestrained at the time of a crash, children become flying missiles, violently impacting the vehicle interior or other occupants, frequently head first.

Studies indicate that children who are unrestrained in passenger vehicles are far more likely to be killed or injured in an accident than those who are restrained. Seat belts alone do not provide maximum protection for small children, although they are far better than letting a child ride unrestrained. NHTSA estimates that over half of the deaths and injuries sustained by young children in automobile accidents could be eliminated by the proper use of child restraint devices.

Many manufacturers are marketing dynamically-tested child restraint devices (CRD). The commercial availability of CRD's and the presence of adult safety belt systems as standard automobile equipment, provide parents with the opportunity to provide effective occupant safety for their children. Because of the availability of such equipment some professionals have expressed the opinion that failure to use such protective devices constitutes a form of child abuse.

Adults should be made aware of the danger of holding a child in their laps. Generally, in the event of a crash, the child will be caught between the adult's body and the instrument panel. The weight of the aduit falling against the child will increase the child's injuries. Adults should also be made aware that they cannot hold on to a baby in a crash. A 20 pound infant, in a $20 \mathrm{mph}$ crash, will weigh 400 pounds. Research studies involving simulated crashes have shown that no adult can hold back that much weight.

On January 1, 1978, (following two years of legislative committee consideration and hearings), Tennessee became the first State to have a law establishing safety requirements for child passengers under four years of age. A public information and education program to encourage the use of child restraint devices began at the same time the law went into effect. 
Since the passage of the law does not by itself insure a reduction of deaths and injuries to Tennessee children, the NHTSA and the Tennessee Governor's Highway Safety Program jointly established the Child Passenger Safety Program in Tennessee. The purpose of this program is to publicize the law, to educate the people of the State about the importance of CRD's and to evaluate the effectiveness of the law supported by these efforts. Recent data show that child restraint use has more than doubled since the law was passed. The project began October 1, 1977, and is to continue for a 36 month period.

\section{Position}

States are encouraged to enact legislation to require special protection for young children. Since young children are especially vulnerable and since the ir vulnerability can be reduced only by responsibile adult action, each State is encouraged to enact legislation that will: (1) adopt the Department of Transportation's performance standard (FMVSS 213-80) for child-passenger protective devices; (2) encourage proper conformance to manufacturers' instruction on proper usage and; (3) require the use of such devices whenever childpassengers are present in a motor vehicle.

Further, States are encouraged to conduct aggressive public information and education programs to increase the public's awareness of the need to use CRDs. For example:

- Statewide workshops should be considered to promote child restraint activities at the local, community level;

o Hospitals should include education information on maternity wards and stock CRDs in the hospital gift shop;

- Pre-natal classes should routinely emphasize the use of CRDs as an important part of child care;

- Pediatricians, as well as other physicians, should be made aware of the child passenger safety problem and be encouraged to speak to parents individually about the need to use CRDs';

- Literature which illustrates the child safety problem and the effectiveness of CRDs should be made available for State Fairs, shopping malls, department stores, automobile dealerships, and other appropriate places; and

- Local television, radio and print media should be approached regularly and encouraged to become involved in educating the public in this area.

Loan-a-Seat distribution programs can be an extremely successful means of getting CRDs to reluctant consumers. Parents who hesitate to pay $\$ 35-40$ to buy a CRD are often delighted to rent one for $\$ 15$.

Instructions on the implementation of such a program are available along with other program guidelines in the NHTSA "Early Rider" Package which was developed as a "how to" manual for child restraint promotion programs. Portions of this package pertaining to education and loaner programs are attached. 
Some suggestions for inclusion in media and educational programs are:

- Children under 5 years should use child restraint devices. Larger children should use lap belts. In any case a lap belt is better than being unrestrained.

- Adults should not hold children on their laps.

- Children should not ride in the luggage compartment of hatchbacks or station wagons.

- The hatchback should never be left open when a child is riding in the back seat. 
ACCOMPANYING MATERIAL 


\section{EarlyRider Educational Curriculum}

\section{The health professional's role is protecting the child passenger}

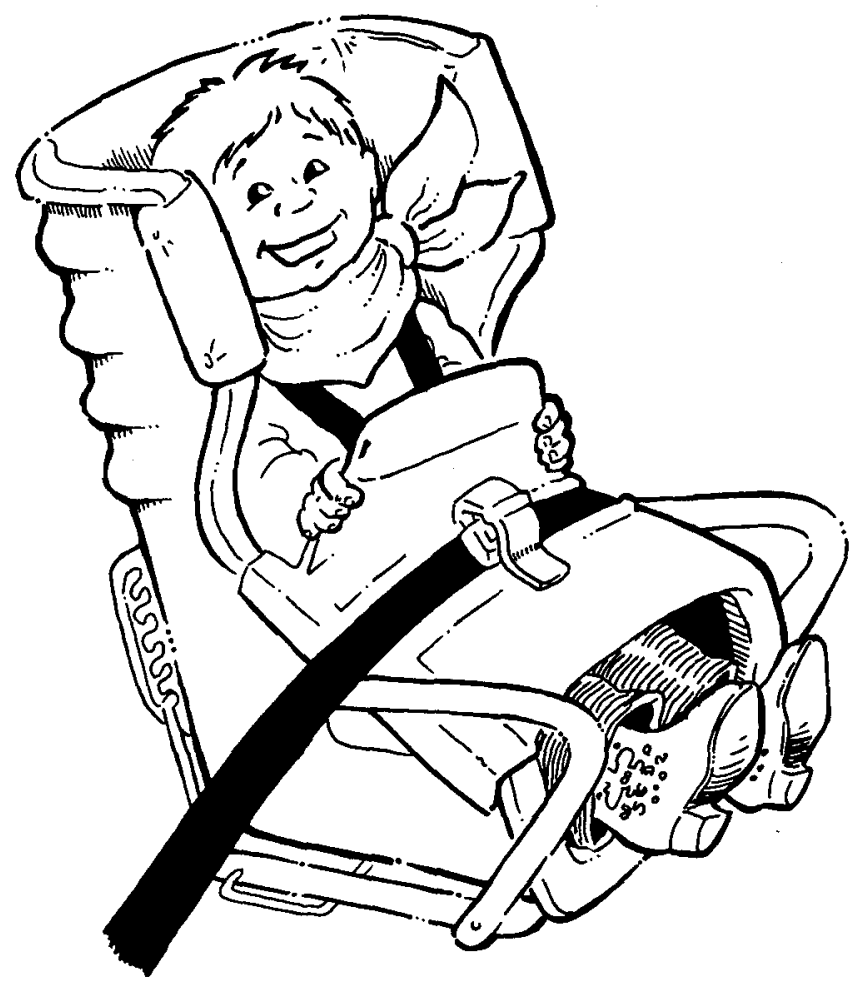

EarlyRider is produced by the National Highway Traffic Safety Administration from materials provided by Michigan's Motor Vehicle Occupant Protection Program, the Michigan Jaycee Auxiliary, and Action for Child Transportation Safety (ACTS). 


\section{Table of Contents}

Chapter 1. Introduction $\ldots \ldots \ldots \ldots \ldots \ldots \ldots \ldots \ldots \ldots \ldots \ldots \ldots, 4$

Chapter 2. Training for Effective Safety Education $\ldots \ldots \ldots \ldots \ldots \ldots \ldots, 5$

Chapter 3. Instructor's Manual $\ldots \ldots \ldots \ldots \ldots \ldots \ldots \ldots \ldots \ldots \ldots \ldots, 10$

Chapter 4. Prenatal Approaches to Safety Education $\ldots \ldots \ldots \ldots \ldots \ldots \ldots, 12$

Chapter 5. In-Hospital Education for the New Parent $\ldots \ldots \ldots \ldots \ldots \ldots, 17$

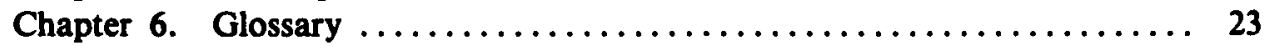

Appendix $A$. . . . . . . . . . . . .

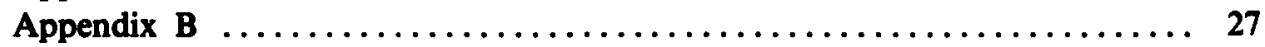




\section{Chapter 1: Introduction}

I. GOAL

The goal of these educational materials for health professionals is to provide the means by which child auto safety can become a routine part of preventive care within the health community. This is done in two ways:

A. by providing an outline of a training course for health professionals, which will assure their understanding of the need to prevent injury to children in auto accidents, and will give them a thorough knowledge of the use and misuse of child restraints.

B. by giving these professionals practical guides to carrying out educational programs specific to the parents they see, and an Instructor's Manual of resource material.

\section{METHODS}

Action for Child Transportation Safety (ACTS) could find no agreement as to effective educational methods among researchers who have investigated various types of child restraint educational programs. Based on the conclusions of these research projects ACTS suggests that future programs will have the most likely chance of success if they incorporate the following key methods:

A. Using health professionals as educators.

B. Informing these professionals adequately about the magnitude of the child passenger safety problem and the methods and problems of child restraint.

C. Making auto safety education a routine part of these professionals' daily interactions with parents.

D. Planning a coordinated program, with multiple exposures of parents to information on child restraint use specifically geared to their immediate needs and concerns.

E. Using a film to effectively portray crash forces and the need for restraint use.

F. Stressing positive aspects of safety, i.e., good parenting, good habit for the child, improved in-car behavior.

G. Making professionals aware of the common types of misuse and their remedies, so they can provide follow-up on restraint use during regular contacts with parents.

III. IMPLEMENTATION

A. Endorsement for the program from professional associations such as the American Academy of Pediatrics, American College of Obstetricians and Gynecologists, American Nursing Association, American Hospital Association, American Red Cross, International Childbirth Education Association.

B. Accreditation of the training course by state or national organizations.

C. Acceptance by local or regional institutions and organizations of participation in an educational program.

D. Training of professionals.

E. Implementation of routine education for parents. 


\section{Chapter 2: Training for Effective Safety Education}

\section{INTRODUCTION}

\section{A. Objectives and Personnel}

1. This training session is designed to give health professionals the motivation, understanding and necessary tools to carry out child restraint education for expectant parents and parents of young children.

2. It is suitable for presentation in several settings:

a. as part of a course of academic training.

b. at a regional or national conference of a professional association.

c. at a local safety conference which members of a variety of health professionals would attend.

d. as in-service education within an organization or institution.

3. Accreditation for in-service education from state or national organizations should be sought to motivate increased interest and attendance.

4. Health professionals for whom this session would be suitable: obstetricians, pediatricians, family practitioners, family and pediatric nurse practitioners, midwives, public health nurses, post-partum nursing staff, childbirth educators, prenatal instructors, health educators.

5. Professionals in related fields who could be involved: family life, parenting, child development instructors, pre-school and day care administrators, driver educators.

\section{B. Teaching Method}

1. Time Element. Allow one to two hours, depending on instructor's teaching technique.

2. Self-Quiz (attached), Give to participants at time of registration so it can be completed before session.
3. Film. "Car Safety: Don't Risk Your Child's Life," by Physicians for Automotive Safety, $16 \mathrm{~mm}, 12 \mathrm{~min}$., color.

4. Handouts for participants. Instructor's Manual (Chapter 3) or selected articles.

\section{PRESENTATION}

\section{A. Professional Responsibility}

1. Auto safety is a new concern.

a. Auto accidents have taken the place of communicable diseases as the leading killer of children over age one.'

b. Car seats designed for crash protection, called "Child Restraints" (CR), have become widely available only in the past five years.

c. Many professionals have had no personal experience with $C R$ or training in injury prevention.

2. Auto restraint use is an emotional topic.

a. Examine personal feelings about safety belt use.

b. Divorce feelings from professional obligation to help protect children.

3. Consider $C R$ use as a form of preventive medicine, like immunizations. They both require parental awareness and repeated actions for adequate protection.

4. Responsibility to teach parents lies with all professionals who specialize in child health.

a. Begins before birth during prenatal care.

b. Continues after delivery, in-hospital.

c. Lasts throughout childhood years.

d. Teaching cannot be limited to one occasion.

1) Parents need and assimilate different types of information, depending on the age of their child.

2) As children grow problems arise, which can lead to misuse or nonuse of CR. 
3) Concern for children's safety by many health professionals stress its importance to parent.

\section{B. Definition of the Problem}

1. Auto accidents are the leading cause of accidental deaths to children. In 1977, among children under age 5:
a. 920 child passengers were killed, about 60,000 injured.
b. 650 died by drowning.
c. 59 died by accidental poisoning.

2. Prevention is possible by use of acceptable CR. ${ }^{2}$

Example: A study of deaths to child auto passengers in Washington State showed that $\mathrm{CR}$ can reduce deaths by $90 \% 0^{3}$

3. Most children do not ride restrained."

a. Most babies ride in an adult's arms, a particularly hazardous spot. ${ }^{\text {s }}$

1) $90 \%$ at time of discharge from hospital.

2) $43 \%$ at $2-4$ months of age.

b. Only $8 \%$ of children under age 5 observed in one study were riding properly restrained in CRs appropriate for their ages.

c. Among the parents who used safety belts, only $22 \%$ of their children were buckled up. ${ }^{4}$

d. Active children riding unrestrained often cause accidents by:

1) Physically interfering with or distracting the driver.

2) Falling out of the car.

4. Many CRs are used incorrectly, reducing protection considerably.

a. Study of infant passengers in CRs showed that more than $40 \%$ of the CRs were not secured with the adult lap belt. ${ }^{5}$

b. Observations of CRs with additional anchor strap required, showed $47 \%$ unanchored."

\section{Crash Protection}

1. General Principles (NOTE: "Automobile Safety Belt Fact Book')

a. The Second Collision or Human Collision is when injury occurs.
Example:

1) Car strikes object head-on, rapidly slows down.

2) Unrestrained occupant continues to move forward at speed of car at time of collision.

3) Second collision occurs, when moving occupant strikes interior of car (which has stopped), or the immovable ground if occupant has been ejected completely.

b. Unrestrained person moves toward impact.

1) Forward into windshield, or over back of the seat ahead.

2) Sideward toward door.

3) Rearward, followed by rebound forward toward dashboard.

c. Person-to-person collisions cause $\mathbf{2 0 \%}$ of serious injuries in one study.

1) Unrestrained person forces another against car interior.

2) Unrestrained person hits a restrained person.

d. How does a safety belt work?

1) It slows occupant down as car stops.

2) It keeps occupant away from interior surfaces of car.

3) It distributes impact forces on strong parts of body structure.

- hips, below vulnerable abdominal area

- chest and shoulder

- wide belt spreads forces.

e. Passive Restraints

1) An air bag works by allowing the body to be slowed down by a soft air-filled bag which inflates momentarily.

- No action is necessary by occupant.

- It only protects front seat passengers from frontal impacts.

- Lap belt is necessary to prevent injuries in side and rear impacts.

- It does not adequately protect babies and toddlers. 
2) Passive Belt consists of a shoulder belt and knee impact pad.

- Belt automatically wraps around occupant when door closes.

- Protects like active belt, but with some force on knees instead of hips.

- CR cannot be secured with it.

2. Protection for Babies and Small Children

a. Show film here (See "Teaching Method" under Introduction),then review points below:

b. Why aren't an adult's arms or lap safe?

1) Crash forces can tear child from adult's grip.

2) Child can be crushed by unbelted or belted adult.

c. Why isn't lap belt adequate?

1) Child's pelvis too small and undeveloped to sustain entire force of whole body during a crash.

2) Positioning a small child so that the lap belt crosses the hips and does not slide up onto vulnerable abdomen is difficult. (NOTE: Using a lap belt is better than allowing a small child to ride unrestrained.)

d. How does a CR work?

1) Its harness or shield distributes impact force over a large body area.

2) The auto safety belt keeps occupants away from car interior or other occupants and prevents ejection.

e. Why should a small baby ride backwards?

1) The CR's back acts like a shield, spreading impact forces over the child's entire back and head.

2) It puts no undue force on any part of body.

3) Harness holds baby in position. (Shoulder straps important.)

f. Features of $\mathrm{CR}$ for child

1) Five-point harness with broad straps spreads force over chest and hips.

2) Shield spreads force evenly over torso, with larger ones cushioning head as well.

3) Anchor straps, required with some $\mathrm{CR}$, work with the car lap belt to keep CR from pivoting forward, bringing child's head near interior surfaces.

g. Baby and child equipment often used in cars but which is not adequate to protect an occupant under crash conditions:

1) "Car" bed, household infant seat, play pen, front carrier.

2) Child car seats made before May 1971, which hook over or under auto seat.

3) Car seats made after May 1, 1971, which meet Federal Motor Vehicle Safety Standard \#213, but do not pass dynamic tests.'

h. Dynamic testing of CR is not required now.

1) Proposed revision of FMVSS \#213 will require it for all infant and child car equipment, but will not become effective until May, 1980.

2) Many CRs have been dynamically tested by manufacturers, Consumers Union,' and the federal government.

i. Instructors must be aware of vast differences in protective value of products:

1) Currently on the market:

- Child car seats which only meet static tests.

- Infant and child CR which pass dynamic tests.

2) Those for sale in the past, now being handed-down or used secondhand.

j. What are the dynamically tested CRs available? $A$ list is the most accurate way of telling, as product advertising is not always clear. One such list is in the EarlyRider Fact Book.

k. How can parents determine which restraint is best?

1) Does the CR fit the child?

2) Does the CR fit the car?

3) How complicated is it to use? (The 
more complicated, the greater the potential for misuse.)

1. Where can professionals and consumers go with questions regarding infant and child auto safety?

1) Action for Child Transportation Safety

2) Physicians for Automotive Safety

3) Various state programs (Michigan, Tennessee, Massachusetts)

4) National Highway Traffic Safety Administration

5) EarlyRider Loan-A-Seat, Appendix G

\section{Instructing Parents}

1. Concepts of Presentation

a. Parents will have own preconceptions about safety belt use.

b. Different approaches will be appropriate with different people.

c. Coordinate your program with any others in community.

d. Gear your information to parents' level of safety awareness.

2. Stress the following points of common misuse or unsafe practices:

a. Use the CR every time your child rides in the car. (Many parents only use a CR when there is no other adult in the car to hold the baby, or only on long trips.)

1) Important for safety purposes.

2) Creates the habit of riding restrained.

- Infants adjust easiest to toddler CR if they have consistently ridden buckled up.

- Toddlers may resist buckling up if occasionally given freedom to roam loose in the car.

- Children who ride restrained usually have improved behavior, making travel more pleasant for all. ${ }^{10}$

- Children riding restrained cannot fall out car doors or interfere with the driver.

- Many accidents happen at low speeds, near home.

- Even a panic-stop can seriously injure an unrestrained child.
3) Use a dynamically-tested CR, and follow manufacturer's instructions.

- Point out label on CR. Instructions there are not complete.

- Instruction sheet or booklet should be read thoroughly and kept for future reference or for others who may borrow or purchase the $\mathbf{C R}$.

4) Parents and others riding in the car should be restrained.

- An unrestrained person can injure a child in a CR.

- Stress that children need their parents to be unharmed, to take care of them.

3. Parental attitudes which may surface and which you must be able to answer:

a. "I'm a safe driver; I won't have an accident."

b. "I'm just going around the block. Children don't have to be buckled up around town."

c. "My new baby is so tiny; and looks uncomfortable. The CR must be bad for his back."

d. "My child complains and fusses to get out."

e. "Restraining my child could restrict her personality development."

4. Demonstration of infant and child CRs.

a. To familiarize professionals with equipment.

b. To set an example of how to teach parents.

c. Follow "Demonstration Techniques" (Appendix A of this booklet).

5. Follow-up program.

a. Effectiveness of education program will depend on the health professional's on-going concern for a child's safety and for helping the adults do a good job of parenting.

b. Repeated contacts with a variety of professionals concerned with CR use is most likely to change parental behavior.

c. Professionals can coordinate their efforts to provide continuity: 
1) Following the child's development.

2) Supplementing information already given to parents rather than repeating it.

d. Emphasis after birth, and after $C R$ is obtained, is on discovering and helping parents correct misuse.

1) Observing the $C R$ in use or in the car is the best way to determine misuse.

2) The majority of CRs are used improperly, and unsafely, due to:

- misunderstanding of often complicated directions.

- lack of knowledge of dangers of improper use.

3) Refer to "Common Mistakes" in EarlyRider Fact Book.

e. Examples of follow-up methods

1) Public Health Nurse, on home visit, has parent give demonstration of how infant is buckled up.

2) Pediatrician routinely asks how baby rides, and asks toddler and older child if they used CRs coming to office.

3) Office nurse or social worker walks new mother to car to observe process of buckling up, or asks parent to bring baby into the office in $\mathrm{CR}$.

4) Childbirth educator reviews procedures at reunion of group after births.

5) Health educator or parenting instructor asks which $\mathrm{CR}$ has been chosen by parents and what problems have come up during use.

\section{REFERENCES}

\section{A. Footnotes}

'National Safety Council, Accident Facts, 1978 edition

2 Williams, A. F., P. Zador, "Injuries to Children in Automobiles in Relation to Seating Location and Restraint Use," Aceident Analysis and Prevention, 9:69, 1977

'Scherz, R., "Washington State Seat Belt Study, 1970-1977" (Unpublished)

- Williams, A. F., "Observed Child Restraint Use in Automobiles," American Journal of Diseases of Chlldren, 130:1317, 1976
' Reisinger, K. S., A. F. Williams, "Evaluation of Program Designed to Increase the Protection of Infants in Cars," Pediatrics, Sept. 1978, p. 280

- National Highway Traffic Safety Administration, The Automoblie Safety Belt Fact Book, 1977

' Huelke, D. F., H. W. Sherman, J. O'Day, "The Hazard of the Unrestrained Occupant," Journal of Trauma, Vol. 16, May 1976. pp. 383-388

'Melvin, J. W., R. L. Stalnaker, "Basic Design Principles of Child Auto Restraints," Society of Automotive Engineers, \#40936

- Consumer Union, Consumer Reports (dynamic tests of child restraints and car seats) August 1972, February 1974, March 1975, June 1977

10 Christopherson, E., “Children's Behavior During Automobile Rides: Do Car Seats Make a Difference?" Pediatries, Vol. 60, July 1977

B. Reading for Course Instructor

1. Articles listed in Footnotes

2. Instructor's Manual

3. Allen, D. B., and A. B. Bergman, "Social Learning Approaches to Health Education: Utilization of Infant Auto Restraint Devices," Pediatrics, Vol. 58, no. 3, Sept. 1976

4. Burdi, A. R., D. F. Huelke, R. G. Snyder, and G. H. Lowrey, "Infants and Children in the Adult World of Automobile Safety Design: Pediatric and Anatomical Considerations for Design of Child Restraints," Journal of Biomechanics 2(3), pp. 267-280, 1969.

5. Kanthor, H. A., "Car Safety for Infants: Effectiveness of Prenatal Counseling," Pedlatrics, Vol. 58, no. 3. Sept. 1976.

\section{Handouts for Participants}

1. Self-Quiz (before session). See EarlyRider Publicity Guide.

2. Chapter 3 of this book.

3. Copies of restraint information from EarlyRider Fact Book.

4. "Common Mistakes Parents Make", from EarlyRider Fact Book.

5. Guidelines for Health Professionals: Appendix B of this booklet.

6. Child Restraint Systems for Your Automobile (pamphlet). Available from NHTSA. 


\section{Chapter 3: Instructor's Manual}

I. Attitudes of parents encountered by safety instructors:

A. Own use of safety belts

1. Rationale for not using safety belts

a. "I won't have an accident, I'm a good driver."

b. "Seat belts are only needed on long trips."

c. "Safety belts can trap me."

2. One survey showed that $50 \%$ of drivers sometimes use belts, but only $20 \%$ always do. Another showed that, when parents used belts, only $22 \%$ of their children were restrained.

B. Feelings about child restraints (CR)

1. Misconceptions that obstruct $C R$ use:

a. Baby should ride in parent's arms, (customary for infant to ride this way coming home from the hospital).

b. Household infant seat belted in front is safe enough.

c. Kids don't like CRs or are uncomfortable in them.

d. $C R$ is too expensive or hard to find in stores.

e. Buckling up children is too much trouble.

f. Child may be trapped in CR.

2. Acceptance of new behavior of buckling up children.

a. Some understand and accept use spontaneously.

b. Some adamantly refuse to use CRs.

c. Majority may respond to information, encouragement, and support in changing to a new habit of buckling up the children (and hopefully themselves).

II. Acceptance Sequence through which parents must go before using CRs successfully. ${ }^{1}$

A. Believe they and their children are vulnerable to auto accidents.

B. Understand that accidental injury can be prevented by $\mathbf{C R}$.

C. Feel that danger is sufficient to outweigh any inconvenience or cost of CR.

D. Learn about $C R$, decide which is best for their needs.

E. Buy and familiarize self with proper use.

F. Proper use on every trip. (Many use CRs incorrectly.)

III. Instructor's Method

A. Provide facts, practical and useful information.

B. Use a combination of approaches keyed to the attitudes of the parents, their progress through the acceptance sequence, and instructor's personal style.

C. Use a persuasive film like "Car Safety: Don't Risk Your Child's Life."

\section{Approaches}

A. Authority-communicate expectancy that parent will use $C R$.

1. "This is part of your layette."

2. "Who hasn't got their CR yet?"

3. "I expect you to take the baby home from the hospital safely."

4. "Don't let me see you without one."

B. Persuasion

1. Scare techniques

a. Anxious parents may shut out extreme messages, so concentrate on minor injuries that parents may have to face, or may have heard of happening to others.

b. Passive parents may respond to this needed incentive.

c. Research indicates that personal accident experience is not related to increased restraint use. ${ }^{2}$

2. Neutral information

a. Bare statistics, non-threatening 
statements ("Cost of CR is about the equivalent of three tanks of gas." )

b. People open to new ideas will respond well, having probably gone through first three steps of acceptance sequence.

3. Positive information

a. Reasons why to use CR, i.e. $90 \%$ decrease in fatalities with $C R$ use, feeling of security and of doing the best for your child.

b. Children have been shown to behave better when they ride buckled up, so the whole family has a more pleasant trip. ${ }^{3}$

c. Provide response for parents who are getting negative feedback from neighbors or relatives ("We never put you kids in belts and you did just fine.") i.e. "This is a new idea, based on new research. Isn't it wonderful that we can take such good care of our baby now."

C. Modeling through positive images

1. A good parent is responsible for and wants to provide a safe environment for child (letting child ride loose has been called "neglected child syndrome")

2. Teach child a health habit, like good eating habits.

3. Be progressive, up-to-date, a leader in new parenting methods.

4. Compare $\mathrm{CR}$ with other types of prevention accepted by parents (locking up medicines, putting gate at top of stairs).
5. Parents who use belts themselves set a good example.

D. Positive Reinforcement

1. Praise parents who bought and regularly use CRs.

2. Let them be "experts" to share information with others.

3. Follow-up by instructor, to check on baby's progress and offer help with problems of CR use, shows that the professional cares what happens to child.

V. Evaluation of presentation, where follow-up is possible.

A. Ask parents who weren't convinced why they don't use CR. What caused them to decide against it?

B. Obtain feedback from those who were convinced as well.

1. Have they had any unexpected difficulties?

2. What would they do differently?

3. Why did the idea of CR appeal to them?

C. Plan future presentations taking this information into consideration.

\section{Footnotes:}

' Becker, Maiman, "Sociobehavioral Determinants of Compliance with Health and Medical Care Recommendations," Medical Care, Jan. 1975, Vol. 13, No. 1, pp. 10-21.

'Siegel, Nakum, "Injuries to Children in Auto Collisions," Society of Automotive Engineers, 1968.

'Christopherson, E. "Children's Behavior During Automobile Rides: Do Car Seats Make a Difference?" Pediatrics, Vol. 60, No. 1, July 1977. 


\section{Chapter 4: Prenatal Approaches to Safety Education}

\section{Objectives}

A. To give parents an accurate understanding of the dangers of not using a child restraint (CR).

B. To demonstrate the correct use of CRs and the reasons why this is important.

C. To show parents how to choose the appropriate $C R$ for them.

D. To persuade parents to use restraints themselves.

\section{Preparations}

A. Study:

1. Chapter 3: Instructor's Manual

2. Demonstration Techniques (Appendix A)

3. Common Mistakes Parents Make (in EarlyRider Fact Book)

B. Obtain Film or Filmstrip, Handouts

C. Obtain CR for demonstration and doll of correct size, or child volunteer

D. Plan your time:

1. 15-20 minute minimum

a. Film or brief talk covering main points

b. Demonstration of how CR works

2. Longer session following outline in detail, with discussion, is preferable.

E. Preview film or filmstrip and rehearse demonstration

\section{Presentation}

A. The number one killer of children beyond the age of one in the United States is auto accidents. (In fact, the number one killer of persons up to age 35 is auto accidents.)

1. In 1977, of children ages 0 through 4

a. 50 were poisoned or died from ingestion of an object,

b. 650 drowned,

c. 930 died as passengers from motor vehicle accidents. ${ }^{1}$
2. "If present trends continue, the average U.S. citizen will have a 50 percent chance of receiving a disabling injury and a 2 or 3 percent chance of dying due to a motor vehicle accident." 2

B. It is estimated that parents can now reduce child auto fatalities by 90 percent by observing two habits:

1. Securing children weighing $\mathbf{4 0}$ pounds or less in specially designed, dynamically tested auto restraints (CRs).

a. Erroneous beliefs leading to non-use of adult or child restraints.

- Myth: Restraining devices are not needed when driving locally at moderate speeds.

Fact: National Safety Council reports that 3 of 4 accidents occur within 25 miles of home and that 50 percent of accidents occur at speeds of $30 \mathrm{mph}$ or less. . . At a speed of $30 \mathrm{mph}$, a $10 \mathrm{lb}$. child (in a head-on crash with a stationary object) is hurtled in the direction of the impact with a force of 300 pounds. (NOTE: The forces involved in a head-on $30 \mathrm{mph}$ crash with a stationary object are approximately the same as those which would be experienced by a person falling onto a sidewalk from a third-story window.)

Myth: Parents will have time to grab a child to protect him or her from an impending accident.

Fact: Most accidents occur without warning, allowing less than a halfsecond to react.

- Myth: Pregnant women should not wear safety belts because the fetus may be killed by the belt.

Fact: The greatest single cause of fetal death in accidents is the death 
of the mother. Although pregnant women are more susceptible to injury by seat belts, the American Medical Association advises that pregnant women are better off belted than unbelted, and further recommends that the shoulder harness be worn to prevent jackknifing forward at hips.

- Myth: People are safer thrown free of the car.

Fact: You are $\mathbf{3 0}$ times more likely to be killed if you are thrown from a car in an accident.

- Myth: An airbag will protect anyone riding in the front seat.

Fact: Small children riding unrestrained can be hurt by airbags if they do not remain seated with their backs against the vehicle's seatbacks, ${ }^{3}$ for example, if they stand up on vehicle seats or sit on the floor under the dashboard.

- Myth: Standard seat belts are adequate protection for everyone in the family.

Fact: Safety belts should be used only as a last resort for children who are under 40 pounds in weight and $\mathbf{4 0}$ inches in height. The very young require specially designed CRs.

b. Differences between children and adults which make specially designed CRs preferable to regular lap belts.

1) Abdominal organs in child's protuberant "pot-belly" are less protected than an adult's because of underdeveloped hips and rib cage.

2) A child's hips not yet developed the front spines (anterior iliac crests) which retain the lap belt on an adult.

3) The head of a young child is proportionately larger with respect to the rest of the body than in an adult, causing greater forward whipping of the upper torso of a lap-belted child.

c. The objective of specially designed CRs is crash protection equal to or better than that afforded adults with the current shoulder-lap belt systems.

1) Current Federal Motor Vehicle Safety Standard (FMVSS) \#213 has regulated manufacture of child car seats since 1971. ‘ The initial requirements of this standard:

a) Did not include infant car carriers.

b) Eliminated seats which "hooked-over" a vehicle seat back.

- These served as launching pads for children hurtling toward windshield in crashes.

- Any found on the secondhand market should be destroyed.

c) Required tests of the strength of the car seat using a "static" test (NOTE: See "Glossary: Chapter 6") which does not simulate crash forces.

2) Beginning in May 1980 , the revised FMVSS \#213 will require dynamic testing and will include infant child restraints.

3) Dynamic-testing of CRs mimics the momentary high-energy forces of a crash using either infant or child-sized dummy. (NOTE: See "Glossary.")

a) Conducted by Consumers' Union over past 6 years.

b) Voluntarily carried out by manufacturers while designing new CRs.

4) CRs which meet dynamic-testing standards.

a) Do not collapse or fracture in such a way as to allow the child to be exposed to potential injury from the restraint itself.

b) Limit forward head movement.

c) Spread impact forces over a wide body area so that no one part bears undue force.

5) Many of the CRs which met the old FMVSS \#213 failed to meet dynamictesting standards. ${ }^{\circ}$ 
a) Some allowed the dummy's head to slam into the simulated instrument panel.

b) Some allowed the seat belt to dig deep into the dummy's abdomen; which, with a real child, could potentially cause severe internal injuries.

6) Types of dynamically tested CRs

a) Rearward-facing infant car carriers give very broad back and head support.

b) Convertible CRs face the rear of a vehicle when used by infants, then face forward when used by older children.

c) Forward-facing child shield-type CRs provide a broad impact surface in front of the child's abdomen and thorax.

d) Forward-facing CRs with 5-point safety harness.

e) Forward-facing 5-point safety harness without a seat, to be used in center rear passenger positions only.

2. Buckling up themselves and every other person riding in their vehicle.

a. The safety of a child's parents is important to the well-being of the child.

1) Parents properly restrained are better able to maintain control in a crash situation than those unbelted.

a) The ability of a driver to stay in position in front of the steering wheel and to regain control of a momentarily out-of-control vehicle is enhanced by use of safety belts.

b) A parent whose injuries are minimized by the use of safety belts is more able to direct or assist a frightened child at the scene of an accident.

2) A parent who protects himself from needless serious injury by wearing safety belts saves his child from needless emotional trauma.

b. Injuries caused or aggravated by one passenger hitting another during a crash are common. Findings of a study of 360 crashes involving a vehicle containing more than one person: ${ }^{7}$
1) One car in 9 had at least one injury associated with occupant-to-occupant contact.

2) "Serious and fatal injuries have been produced in children by impact from adults' bodies."

c. Never buckle 2 people into one safety belt.

1) Neither is securely held.

2) The larger one may crush the smaller.

d. Heavy or sharp objects in the car can also cause injuries.

1) In a head-on crash, the front end of a vehicle dips down and the back rises, throwing unrestrained people and objects upward and forward.

2) Stow these objects in trunk or rooftop carrier.

3) In the cargo area of a station wagon, place objects against the back of the rear passenger seat.

e. Make buckling up a 100 percent habit.

1) It's easier to start a habit with a marker event, i.e., the first trip home from the hospital with a new baby.

2) Child becomes accustomed to riding in his CR.

a) Older children may eventually refuse to ride unrestrained.

b) However, expect balking and attempted escapes from CRs for short periods of time between the ages of 9 months and 2 years. (NOTE: Often these bursts of independence and drives for freedom coincide with new crawling, walking, and talking skills.)

c) If a child does fuss excessively or get out of CR, parent must teach that this is unacceptable.

- Children can get out of most CRs if they are determined.

- Find a safe place to pull off the highway.

- Stop the car.

- Put the child back into the CR.

- Tell the child that riding out of his CR will not be tolerated.

3) On long trips plan ahead.

a) Allow for 10-minute stops every hour so babies can be changed, etc. 
b) Have an adult or older child talk to baby, offer play with hands or feet.

c) Nursing can be done without removing baby from carrier, or during rest-stop.

d) If bottle feeding, use plastic bottle, not glass.

4) In an emergency, when there are not enough safety belts for all the people in a vehicle:

a) Place an unrestrained baby in padded box behind rear seat (not under people's feet).

b)Put child either sitting or standing on the floor of the rear passenger compartment. This is not safe, but better than having children ride on laps.

C. A second major benefit of buckling up children is their improved behavior while in the car. A Kansas University Medical Center researcher found that:

1. Children riding in car seats exhibited much higher levels of appropriate or safe behavior than those riding loose.

2. When car seats were introduced to those children who previously had not used them, the level of appropriate behavior improved dramatically, and were still effective at three-month follow-up.

D. In order to obtain the protection offered by a CR, it must be used exactly as recommended by manufacturer, with the exception of using any optional reclining mechanism.

1. Use of optional reclining positions on some CRs reduces their crash protection because they tend to:

a. Decrease the amount of back support of rearward-facing infant $C R$, placing higher impact forces on a smaller portion of the upper back and on the shoulders where the harness straps lie, and

b. In a reclined forward-facing $\mathbf{C R}$, there is an increased potential for concentrating impact forces on the child's spine.

2. Most CRs are not used correctly. In an observational study conducted in 1974, three-quarters of the CRs were either installed and/or used improperly.'
3. Failure to follow manufacturer instructions means that:

a. The purchasers of the CR are not getting what they often paid extra dollars for-crash protection.

b. They may be placing the improperly secured child in danger of greater injury than if the child were simply buckled in with the vehicle lap belt.

4. Carry out demonstration of infant $C R$. (NOTE: Follow "Demonstration Techniques," Appendix A.)

E. There is currently no one "best restraint." Each restraint must be judged for its appropriateness in light of each family's needs and automobile size.

1. Problems can be avoided by careful consideration of:

a. Fit of $C R$ in family car(s).

b. Convenience of CR in daily use. (NOTE: See EartyRider Fact Book.)

2. Shopping information for parents:

a. EarlyRider Shopping Guide.

b. Local shopping list-with comparative prices and information on CR loan or resale program.

F. Expect changes and further improvements in child auto restraints. Today's dynamically tested models can be expected to appear old-fashioned in coming years.

1. As recently as 1970 , there was no government safety regulation for CRs.

2. In 1971, FMVSS $\# 213$ went into effect.

3. Expect a government standard requiring dynamic-testing by May 1980 .

G. Parents must be prepared for resistance from others (friends, relatives) who never used a crashworthy CR or do not use safety belts. They may wish to respond to their criticisms with messages like these:

1. "Parents a generation ago could do little to protect their children from measles, mumps, and rubella. Today I have my children immunized. Likewise, parents of my generation could do little to shield their children from injuries and deaths associated with auto accidents. I feel so lucky that 1 can now protect my children by using these crashworthy auto restraints." 
2. "Statistically, auto accidents are the number one threat to my children's lives. I can wipe out 90 percent of that threat simply by having my children properly buckled into crash-tested auto restraints (car seats) every time they ride in a motor vehicle."

\section{REFERENCES}

Background reading:

Cohen, Martin, "Innocent Victims, Innocent Killers," Redbook, October 1974, pp. 55-58.

Fales, Edward, "Belts on, Buttons down: What Every Mother Should Know about Car Safety," New York, Delacorte Press, 1971.

Kelly, A. B., "Passive vs. Active Equals Life vs. Death," Society of Automobile Engineers, Inc., 2 Penn Plaza, NY, NY, 750391, Feb. 1975.

Melvin, J. W. and R. L. Stalnaker, "Basic Design Principles of Child Auto Restraints," Society of Automotive Engineers, 740936, Oct. 1974.

Moon, Joy and Jan Nicol, "The Neglected Child Syndrome: The Infant and Child in Automobile Collisions," Children's Automobile Safety Research Committee, Consumers Assn. of Canada, 1973.

Shelness, A. S. and Seymour Charles, "Children as Passengers in Automobiles: The Neglected Minority on the Nation's Highways," Pediatrics, Vol. 56, No. 2, August 1975.

Siegel, A. W., Nahum, and Appleby, "Injuries to
Children in Automobile Collisions," Proceedings, 12th Stapp Conference, Society of Automobile Engineers, 1968.

Snyder, R. and B. O'Neill, "Are 1974-75 Automobile Belt Systems Hazardous to Children?" American Journal of Diseases of Children, Vol. 129, Aug. 1975, pp. 946-949.

Williams, Alan, "Warning, in Cars Parents May be Hazardous to their Children's Health," Insurance Institute for Highway. Safety, 1978.

\section{Footnotes}

' National Safety Council, Accident Facts, 1978 edition.

2 Scherz, Robert, "Restraint Systems for the Prevention of Injury to Children in Automobile Accidents," Am. Journal of Public Health, Vol. 66, May 1976, pp. 451-456.

"Patrick, Lawrence M., Gerald Nyquist, "Airbag Effects on the Out-of-Position Child," Soc. of Automotive Engineers, $\# 720442$.

- National Highway Traffic Safety Administration, "Standard No 213, Child Seating Systems, \#571.213," 49 Code of Federal Regulations, 1974, pp. 606-610.

' Consumers' Union of United States, Inc., "Car Safety Restraints for Children," June 1977, pp., 314-317.

- "Crash Tests of Car Safety Restraints for Children," August 1972, pp. 484-489.

' Huelke, D. G., H. W. Sherman, and J. O'Day, "The Hazard of the Unrestrained Occupant," Journal of Trauma, Vol. 16, May 1976, pp. 383-388.

- Christopherson, Edward, R., “Children's Behavior during Automobile Rides: Do Car Seats Make a Difference?" Pediatrics, Vol. 60, No. 1, July 1977, pp. 69-74.

- Williams, Alan F., "Observed Restraint Use of Children in Automobiles," Insurance Institute for Highway Safety, Washington, D.C., May 1975. 


\section{Chapter 5: In-Hospital Education for the New Parent}

\section{INTRODUCTION}

Since the vast majority of babies are born in hospitals or birth centers, the in-hospital stay is an ideal time for reaching those parents who have not attended prenatal classes nor will take part in parenting groups later.

Also, parents are likely to be aware of the fragility of a new-born and eager to learn how to take proper care of their baby.

A third benefit of in-hospital education is to promote the establishment of a safe pattern of behavior before an unsafe one is begun.

Since parents' interest is usually limited to the immediate care of the baby, however, they should not be expected to absorb information on specific measures for toddler or older children, which should be available later, through pediatricians and/or various parenting classes.

"CR" is used to mean crashworthy car restraint, one listed in accompanying pamphlets as having passed dynamic tests. Instructor can choose word to use with parents, defining the choice. See "Glossary" chapter 6.

\section{GOALS}

A. Parental awareness of reasons for carrying their baby in $\mathrm{CR}$.

B. Purchase or loan of CR for each baby.

C. Parents able to use CR properly, with understanding of why proper use is important.

D. Each baby leaves hospital in CR.

III. PERSONNEL (In order of preference. All should receive adequate training.)

A. Post-Partum nursing staff.

B. Health Educator.

C. Volunteer.

D. Adequate training is essential for all involved.

IV. ROLES OF OBSTETRICIAN AND PEDIATRICIAN, AND PEDIATRIC NURSE PRACTITIONER

They should be made aware of program and encouraged to routinely give brief verbal support to use of $C R$ during in-hospital contact with parents.

\section{PREPARATION}

A. Coordinate program with any other being carried out locally, to complement rather than duplicate.

B. Train personnel.

C. Arrange for routine showings of film or filmstrip on $O B$ floor video-tape, closed circuit TV, film-strip projector, or $16 \mathrm{~mm}$ film projector, depending on whether individual or group showings are desired.

D. Order handouts, film or filmstrip.

E. Arrange for time and space for routine educational sessions.

F. Obtain demonstration $C R$, as described in Demonstration Outline. This might be donated by local merchant.

G. Prepare local availability/price list (see sample in EarlyRider Loan-A-SeatAppendix B).

\section{AUDIO-VISUAL AIDS}

A. Films

1. Most suitable film: "Car Safety, Don't Risk Your Child's Life."

2. Most suitable filmstrip: "Do You Care Enough?"

3. Film is preferable because it demonstrates crash forces impressively, while filmstrip can only imply them. Your choice may depend on equipment available.

B. Flip Chart Development is suggested to help instructors who can use neither film nor filmstrip.

\section{HANDOUTS FOR PARENTS}

A. Pamphlet, "This Is the Way the Baby Rides," Action for Child Transportation Safety, focuses on protection for infant, with list of infant CRs and Convertible CRs. 
Stamp with local address for more CR information.

B. "Child Restraint Systems for Your Automobile," an aid in choosing a CR, helps parents avoid some of the problems which lead to misuse. Available from NHTSA.

C. EarlyRider Shopping Guide and Local Availability/Price List-containing comparative prices, local loan or resale programs, local organization (if any) which helps with problems arising during use of CR. See Appendix B, EarlyRider Loan-ASeat.

\section{INITIAL POST-PARTUM CONTACT} (with individual parent)

A. Scheduling

1. Should occur after pediatrician's first visit, prior to film or other educational session (if given) because:

a. Parent's prime concern for baby's condition is relieved.

b. Prompt discussion conveys importance.

c. Prompt discussion gives parent opportunity to obtain $\mathrm{CR}$ before discharge.

d. This may be only contact, due to early discharge, or staff shortage.

2. Five-minute duration. This should be made part of a routine contact between new mother and member of nursing staff.

B. Content

1. Find out how parents plan to transport baby home.

2. Parents with recommended CR:

a. Praise, find out whether they understand significance of its crash protection, whether they have used $\mathbf{C R}$ before.

b. Give pamphlet. Point out local address or telephone number on pamphlet which parents can use if they have problems in use.

c. Invite to upcoming film or educational session, especially to see how to use CR for a newborn. Ask to bring pamphlet to session.

3. Parents without $C R$ : a. Give brief explanation of problem: Most people don't like to think about it, but the fact is that more children die in the family cars than in any other way.

- Parent's arms are not safe in a crash, because baby can be thrown out violently.

- Injury can happen even in a minor accident.

- The force of a $30 \mathrm{mph}$ accident is like falling out of a third-story window onto a sidewalk.

b. Give brief explanation of solution:

- A new idea in baby care:

- CRs can prevent most deaths and injuries to babies.

- Carbeds and household infant seats give no protection.

- Dynamically tested CRs are needed for infants and children.

c. Give pamphlet (point out list), Which Restraint Is Best for My Child? local availability/price list.

d. Invite to upcoming film and/or educational session.

4. Ask all to bring 'CRs to hospital at time of discharge, with directions, two extra receiving blankets and towel.

\section{FILM VIEWING}

A. This may be the most convincing element of program. Suggested film or, to a lesser degree, the filmstrip will answer many parents' questions, making extended discussion less necessary.

B. System of viewing must be adapted to each institution's equipment and method of presenting other educational programs.

1. Individual viewing depends on parents' interest, and cannot be followed immediately by discussion.

2. Group viewing takes time during educational session, but assures that parents see it, and allows for immediate followup.

\section{FORMAL EDUCATION SESSION}

A. Schedule

1. 20 minutes maximum 
2. Include film or filmstrip (See section on AVAs) unless it has been viewed individually. Otherwise use flip chart.

3. Alternate days with bath/feeding demonstration in busy schedule.

B. General Concepts of Presentation

1. Keep in mind parents' personal viewpoints.

a. Perception of vulnerability to danger?

b. Active or passive in determining own life?

c. Car safety preconceptions and practices.

d. Special situations or cultural traditions (i.e., grandmother in charge of baby's care).

2. Stimulate interest in purchase of $C R$ and proper use.

3. Focus on first ride home from hospital.

C. Curriculum

1. Introduction: "Your babies can consider themselves very lucky to be born now. They can be protected from all sorts of hazards from which we suffered as youngsters. Immunizations for childhood diseases and safety caps to prevent poisoning, make their world very different from 20 years ago. Now the family car is the greatest threat to their health. Car safety is a very new idea in baby care. Only within the past five years has it become practical for most children to be protected in the car. The hospital staff wants to help you make sure your baby gets home safely, and never has to come back for an emergency visit."

2. Basic facts: Find out how many have read pamphlet, seen film or filmstrip. Use this base of information to review basic facts.

a. Ask if parents found any surprises in film.

b. Force of crash-hard to imagine. Calculate this simply: weight $x$ speed. How much force would a 10 lb. baby have in $30 \mathrm{mph}$ crash? 300 lbs.

When baby has grown to 20 lbs., at 30 mph? 600 lbs.

c. Parent's arms cannot hold baby under these conditions. Child in lap can be crushed by parent's body, especially if the adult is also unbelted, or if both are buckled into one belt.

d. Unrestrained passengers often injure others-force of $100 \mathrm{lb}$. older child or mother in $30 \mathrm{mph}$ crash is $\mathbf{3 , 0 0 0} \mathrm{lbs}$.

e. Children riding loose can be seriously hurt by "minor accidents" or panic braking to avoid an accident.

f. CR use improves behavior of children, leads to happier trips for the whole family.

3. Essential features of $\mathbf{C R}$

a. A strong container that won't break under crash forces.

b. Container should be anchored to car and child held in container so child won't hit interior or be thrown out of car.

c. Container should spread the force over a large area of the body rather than concentrate it on one point. For infant, head, neck and torso should be cushioned.

Illustration: toddler bumping head on pointed corner of table vs. bumping on flat surface. Which more painful?

d. Question: How do babies commonly ride? Can these give adequate protection?

- Parent's arms

- Car bed

- Loose on seat

- Household infant seat

- Front carrier

e. CR fulfills these qualifications-can reduce deaths by $90 \%$, injuries by $60 \%$.

- Those recommended have been designed and tested for crash protection. Made of special materials, with certain type of harness, method of attachment to auto lap belt.

- Infant CR, suitable from birth to 9-12 months, faces rearwardshow demonstration $C R$, point out harness, place for lap belt.

- Child CR, used from time outgrow Infant model, to about four years 
of age. Give brief description, referring to film or flip chartchild faces forward, sits upright, held with lap belt, child harness and/or shield. Some need anchor strap at top, essential for safety.

- Center rear seat is safest place in car, except when driver must closely supervise child, then put in front.

f. Safety depends on CR use on every trip.

- “. . A fatal accident can happen to a competent driver at low speed, as it did to us at $25 \mathrm{mph}$. We had made a rare exception to faithful use of our small son's car seat, and he died instantly. Children depend on their parents' precautions. They cannot say, 'Buckle me.' " (Letter to Consumer Reports, June 1974.

- Consistency also important for developing habit of riding buckled up. It is much harder to get a baby or young child to buckle up, if it is not expected on every ride.

4. Proper use of $C R$ is essential, but many parents do not follow the directions.

a. If not done, not only is protection lost, but your money has been wasted.

b. Instructions given by manufacturer are on separate sheet or booklet. Label on CR is incomplete.

c. Read instructions twice, keep for future reference or to pass on with $\mathrm{CR}$ given away or sold second-hand.

d. Conduct demonstration. Arrange in advance to use one new baby for this, rather than a doll, if possible. (Refer to Infant CR Demonstration Techniques, Appendix A.)

5. Guidelines for choosing CR (refer to EarlyRider Fact Book.)

a. Point out list in book. These are current models which have been designed for crash protection and "dynamically tested." Some car seats for toddlers do not give crash protection.

b. Look for $C R$ the correct size for child.

c. Find CR to fit your car-try before you buy. d. Read directions, not just label. Will you be able and willing to buckle it up properly every trip?

e. Infant CR: less immediate cost, possible loan program availability; can get toddler CR later, look for secondhand one.

f. Combination Infant/Toddler CR: only one purchase necessary, but may be complicated to alter for toddler; look at toddler features when you buy, try in car both ways. Check for anchor strap in toddler mode (can you cope with installing this?) Be sure to keep directions for later reference.

g. Shop around for best price-refer to local comparative price list.

h. Where to turn for help or further information as baby gets older?

- Local CR educational program (if any).

- State CR program (Tennessee, Michigan, Massachusetts and others have them).

- Action for Child Transportation Safety, P.O. Box 266, Bothell, Washington 98011.

- Physicians for Automotive Safety, P.O. Box 208, Rye, NY 10580.

- EarlyRider, NHTSA, NTS-14, Washington D.C. 20590

6. Repeat request to have family member bring $C R$ to hospital at discharge time, with directions, two receiving blankets, large towel.

7. Discussion

a. "You must all feel very much how helpless your new babies are, and how heavy your responsibility is to bring them up. Think of yourself as teacher, not just guardian. Looking ahead, in what ways can you think of yourself teaching baby to be safe, to make your burden lighter?"'

- Not to play with electric plugs.

- Not to put small objects in mouth.

- Not to crawl downstairs head-first.

- To ride in a CR.

b. "Parents also protect children from many hazards by limiting their access to them. In what ways can you see yourself doing this?" 
- Keeping razors or knives out of reach.

- Putting cleaning chemicals out of reach.

- Shutting a gate across the top of the stairs.

- Buckling up child in CR.

c. "Knowing what you do now, do you feel CRs are too expensive?"

- Every child's life is worth the expense.

- CRs are cheap insurance and better. The payoff comes before the injury happens, not just afterwards to patch up a smashed nose, a broken leg, or worse.

- Compare to cost of medical care, even just trip to Emergency Room to see if a bloody nose is the only injury from a panic stop.

- Compare to cost of other baby equipment: cribs, high-chairs.

- CR can often be obtained secondhand, have high resale value.

- Use gifts of money to the baby toward the purchase.

d. What would happen to baby if you were injured and hospitalized now? Baby needs both parents healthy-use your belts too.

8. Additional points for discussion, depending on time available.

a. Can baby sleep in CR?

- Yes, car's motion helps.

b. Is the reclining position bad for baby's back?

- No, babies need not always lie flat. In many cultures, babies always ride on mother's back, sitting vertically.

- During long rides, stop and give baby a chance to stretch and change position every hour or two.

c. What if baby fusses?

- Many reasons for fussiness-don't assume it is CR. Is baby tired, hungry, wet, or in need of companionship?

- If baby falls asleep in car, plan long trips for nap time or drive at night.

- You can sit next to baby, talk and sing, if not driving. You can play with baby's hands and toes. Soft toys can be given-nothing hard or sharp. If music is soothing, try a tape-cassette player.

- If you let baby out of CR when car is going, you are breaking the habit-baby quickly learns that fussing will get him the reward of being picked up and held. This will give you added trouble in the long run. Baby can also learn that in the car he or she will not be picked up. Parallel: Would you let toddler play with knife just because he or she pestered you to get it?

d. Can I feed my baby in the CR?

- If nursing, either stop the car, remove baby and nurse, or nurse while baby is in CR (this can be done).

- A bottle can be given, preferably plastic to prevent breakage in event of accident.

e. Sharp or heavy objects (i. e., groceries, tools) should be carried in the trunk or on the floor behind the front seat. They can cause serious injuries to your well-protected child. Also, make sure $C R$ is buckled in with lap belt, even when baby isn't riding in it, so it doesn't get thrown around in crash.

f. What if baby rides in another car, with baby sitter, grandparents?

- Transfer CR to other car.

- Tell other drivers why and how CR is to be used. You can insist on cooperation when your child's safety is involved. You should also insist that the other passengers wear safety belts too.

- Tell them you are not worried about their driving ability, just the chance that another driver will cause an accident involving them.

- If they don't cooperate, don't let baby ride with them. It is easier to live with their hurt feelings than your guilt if your child is needlessly hurt.

g. What if I have to take the baby in a 
car without enough belts or space for CR?

In an emergency, when there is no way to take another car, baby would be best off on the floor behind the front seat (but not under adult's feet) or held by a belted adult in rear seat. Remember, this isn't really safe.

\section{DISCHARGE PROCEDURE}

A. If parent has not attended a formal session, ask if any questions on pamphlet or film.

B. If $\mathbf{C R}$ is present:

1. Have parent place child in CR, fasten harness, referring to instructions if necessary. (It is easier to confirm correct use or deal with problems in room rather than car.) Commend parents.

2. Carry baby in CR to car.

3. Have parents secure $C R$ into center back seat (preferably with lap belt). Suggest that mother sit beside baby, also buckled up. Commend parents, and remind the mother that she will have plenty of time to hold baby safely at home.

4. If instructor cannot accompany parents to car, for hospital liability reasons, discuss correct placement, referring to instructions.

C. If no CR is available:

1. Suggest mother ride in rear seat, with safety belt, holding baby. This would be suitable if the car is crowded with friends and relatives.

2. Suggest that all passengers wear their belts to protect the baby.

D. Remind all parents to use CR on every trip the baby takes. 


\section{Chapter 6: Glossary}

Child Restraint: abbreviated throughout this set of educational materials as "CR"-a device designed to protect an infant or child passenger from injury in an auto collision, and which has passed dynamic tests. There are many other words in use, some of which have misleading implications, so be sure to define for your audience whichever word you feel comfortable using. "Car seat" is used by manufacturers but may imply oldstyle, or static tested seat; "infant seat or carrier" implies flimsy household baby holder; "car restraint," word "restraint" may have negative connotations or seem too technical; "safety seat" and "infant car carrier" are neutral, nontechnical words easily used in teaching.

Three-point Harness: two suspender-like shoulder straps, one crotch strap.

Five-point Harness: two shoulder straps, one crotch strap, two hip straps.

Shoulder-strap Retainer: a strap or metal clip which holds two shoulder straps together so they won't slide off the infant's or child's shoulders. Called "retainer strap," "harness tie strap," "shoulder belt retainer strap" by various manufacturers.

Anchor Strap: ("tether," “tie-down strap"):

Top: a single strap of harness webbing extending rearward from the top rear center of a child's CR to a bolted anchor plate on the rear window ledge or elsewhere behind the rear passenger seat. If the $C R$ is positioned in the front passenger seat, the strap extends back to the tongue portion of a rear lap belt. The strap must be pulled tight to keep the CR from collapsing or pivoting forward during frontal impact.

Side: a strap of harness webbing extending from the top rear side of a CR inboard to the anchorplace of the adjacent passenger lap belt. It must be tight to keep CR stable during side or quartering impacts.

Barrier Shield, Impact Shield: a large, padded, somewhat flexible, C-shaped restraint surface that sweeps up close to the child's abdomen, then bends away from the child's chest and face. It distributes impact forces over a large body area. The auto lap belt wraps around the front of the shield, never touching the child.

Static Test: the type of test employed since 1971 to regulate the manufacture of children's car seats under Federal Motor Vehicle Safety Standard (FMVSS) \#213, and now considered inadequate. The test involved application of an increasing forward pull up to a force of 1000 pounds, upon a wooden block shaped like a child's torso, which is strapped into a car seat on an auto seat bench. The seat passes the test if it retains the torso block within its harness or shield and allows no more than 12 inches forward movement of the block.

Dynamic Test: (This type is proposed for all infant and child car equipment made after May, 1980.) During the past seven years, varying dynamic tests have been run on CRs claiming crashworthiness. These vary in their details according to the laboratory performing the tests. A CR containing an infant or child-sized dummy is subjected to impacts simulating the intense, splitsecond forces of auto collisions. These are usually done at $30 \mathrm{mph}$ in the frontal direction, 12 to 20 $\mathrm{mph}$ in the side, quartering, and rearward directions. A CR passes the tests if it retains the test dummy, if it suffers no loss of structural integrity, and if the CR limits head motion of the dummy to the distance considered "safe" by the test engineers. Experts have disagreed over interpretation of test data on allowable limits for safety.

Inertial Reel Safety Belt: this relatively new type of adult safety belt has a one-piece lap/shoulder belt which only locks on impact. This permits the lap portion to move in and out with the wearer's normal motion. The lap belt cannot be fastened tightly about a $C R$, as it must do to hold it in place during daily use. A locking clip enables the lap portion to be tightened. New, non-tightening, lap-only inertial reel belts cannot be made to hold a CR. 


\section{Demonstration Techniques for Infant and Child Auto Safety Restraints (CR)}

NOTE: Sections marked ${ }^{*}$ apply only to demonstration of child CR.

\section{CHOICE OF A MODEL FOR DEMONSTRA- TION}

A. Model should illustrate as many of the following features as possible:

1. 3-point or 5-point safety harness

2. Shoulder strap retainer

3. Adjustable reclining mechanism

4. Top anchor strap, for use in forwardfacing position of convertible or child CR

a. Expectant parents should be shown this as it may influence their choice of a convertible model for the baby.

b. Neglect of anchor strap very common, serious problem.

c. This is stressed in film, "Don't Risk Your Child's Life."

B. Doll or child is essential for use in demonstration.

1. For infant: Baby doll, 20-22" long, or baby if available.

2. For toddler: Large doll or child of adults attending educational session (arrange in advance).

C. Ask sales managers of local CR retail outlets for donation of demonstration model and doll to your program, in exchange for a simple label on the CR stating donor's name.

\section{STEPS IN DEMONSTRATION}

A. Become familiar with $C R$ before actual presentation.

B. Discussion of common features

1. Point out where the instruction labels may be found glued onto the CR itself.

a. Show detailed instruction sheet or manual which should be read twice before attempting to use the CR.

b. Urge parents to keep the additional instructions in a safe, yet accessible place for use by others using the CR.

1) Grandparents

2) Babysitters

3) Buyers of second-hand CRs.

2. Point out any reclining mechanisms.

a. Use of the extremely reclined positions reduces crash protection of infant CR.

b. Recommend that parents use only the manufacturer's first-listed or preferred infant position in a moving vehicle.

*c. Reclining forward-facing $C R$ also gives reduced protection.

3. If the energy-absorbing padding on the CR is plastic, the parents may wish to cover it with a home-made terrycloth cover to-

a. Increase the warmth of the padding in winter, and

b. Decrease the heat and stickiness from perspiration in summer.

4. Discuss some reactions parents can expect from newborn when first placed into the CR.

a. An alert baby in a room full of tense, anxious adults will probably sense the emotional climate and react by crying.

b. A wet or hungry baby may also cry.

c. To help smooth discharge from maternity ward, warn parents it will take at least 15 minutes for-

1) Review of the $C R$ instructions

2) Adjustment of the harness straps.

C. Placing child or demo-doll into the $C R$

1. If a convertible $C R$, point out adjust- 
ment points for the harness straps and correct the position for infant or child.

2. Discuss appropriate dress for the infant:

a. No bulky clothing which could displace shoulder straps,

b. No heavy blankets or buntings between the infant and the harness.

3. Place infant or doll buttocks first into CR. (NOTE: Putting an infant in shoulders first may increase slouching.)

4. Pad each side of infant or doll with a receiving blanket or the equivalent rolled lengthwise so it extends from the thighs to the top of the head.

*5. Place child in CR sitting straight with buttocks against back of $\mathrm{CR}$.

6. Adjust harness to fit.

a. Cross chest with shoulder straps if directed to do so by manufacturer (Bobby-Mac infant position).

b. Check that crotch straps are properly looped and mention that their function is to keep hip straps low.

c. Tighten the harness.

1) Allow no more than 1 inch or 2 fingerbreadths clearance between the doll's chest and the harness.

2) Explain the consequences of too loose a harness.

a) Infant or child may slip out of the harness on impact.

b) Infant or child may be subjected to a dangerous magnification of impact forces due to sudden jolt from hitting the previously slack harness.

d. Emphasize proper rethreading of single buckles on harnesses. (NOTE: Single buckles will not secure straps unless correctly relooped.)

e. Demonstrate placement of shoulder strap retainer and mention its purpose is to keep the shoulder straps from sliding off the infant's sloping shoulders.

7. Secure any padded armrests with appropriate straps to prevent their flying upward in a crash. (Stress that armrest is not a safety feature and can be permanently removed.)
D. Placing child and $C R$ into family vehicle:

1. Tubular bases on some CRs may mar the vehicle's upholstery.

a. Protect the upholstery with a blanket or vinyl tablecloth.

b. Use the blanket or tablecloth to cover the $C R$ when the vehicle is parked in the hot sun.

2. Preferred location in vehicle is the rear center passenger seat, unless driver/parent must constantly turn around to check on infant or small child.

a. CRs are to be used only on forwardfacing vehicle seats.

b. CRs are to be used only on seats with locking seat backs.

c. Infant $\mathrm{CR}$ should not be placed facing a vehicle seat-back with inset radio speaker or fold-up armrest.

d. The infant in CR should never face a division between the front folding seat backs of 2-door sedans or the space between 2 bucket seats.

e. Adjustable head restraints should be in the down position.

3. CRs cannot be effectively secured with emergency-only locking inertial reel lap belts or passive belt systems.

a. Locking clip can make inertial reel belt usable. (NOTE: Refer to "Glossary," Chapter 6.)

b. With passive belt, use $C R$ only in seating position with regular lap belt or install regular lap belt in front right seat.

4. All infant CRs or convertible models used for infants (with the exception of the sideward-facing Sweetheart II Models) face the rear of the vehicle. Turned around in the forward-facing direction, they would either-

a. Concentrate impact forces on the infant's shoulders or

b. Throw the infant out of the CR completely.

5. A few CRs require use of a side anchor strap when placed in other than center locations in the vehicle.

a. The strap keeps the CR from tipping toward side of car. 
b. The strap is easily threaded around the base of the next inboard set of seat belts.

6. Level the base of the Infant $C R$ to horizontal position if recommended to do so by the manufacturer.

a. The leveling helps maintain the proper angle of back support for the infant.

b. Be careful not to tilt the CR farther since that may allow the infant to be thrown forward between shoulder straps.

7. Placement of vehicle seat belt:

a. Read instructions regarding where to put any attached vehicle shoulder belts.

1) One model CR (Sweetheart II) cannot be used where the shoulder belt cannot be disconnected from the lap belt.

2) Use locking clip to tighten the lap portion of continuous loop lapshoulder belts.

b. Make sure of correct placement of belt around or through CR.

c. Pull lap belt tight when you fasten $C R$ into place, while pressing $C R$ down against vehicle seat.

d. Parents of older infants may turn over any lap belt buckle directly in front of the infants to decrease the chances of unbuckling by playful fingers.

8. Place any blankets necessary for warmth on top of the harnessed infant.

9. Buckle up everyone else in the vehicle.

10. Whenever the CR sits empty in a moving vehicle, it should be buckled to keep it from becoming a flying missile in a crash.

11.Infant outgrows infant $C R$ or infant position of convertible model when, according to manufacturer's instructions:

a. Weight and height maximums are reached.

b. Baby can sit upright unsupported.

E. Permit parents to handle $C R$ and doll after demonstration. Give appropriate pamphlets and shopping information 
A good community-wide program for the prevention of child auto deaths and injuries through the promotion of crashworthy restraint systems-infant and child car carriers, harnesses and auto lap and shoulder belts-could be organized by health professionals.

A. Obstetricians, Family Practice Physicians and/or Their Office Personnel, Midwives and Childbirth Educators Could:

1. Bring up and sell the idea of crashworthy car restraints to expectant parents. If possible, demonstrate proper use of a crashworthy infant car carrier.

2. Hand out literature about crashworthy car restraints and what to consider before buying one.

3. Encourage the purchase of a crashworthy car carrier before delivery, to use when leaving the hospital. [Car carriers for loan may be available in some communities.] Have parents test the car carrier in their vehicle for fit and to make sure the lap belts are long enough to go around it.

4. Follow up at the postpartum checkups. Encourage consistency of restraint use. Determine if any problems have been encountered.

B. Postpartum Ptrsonnel Could:

1. Bring up and sell the idea of crashworthy car restraints, perhaps using video cassettes.

2. Hand out literature to those without car carriers and to those with nonconvertible infant car carriers that necessitate the later purchase of a second, child-sized restraint, usually within a year from the child's birth.

3. Advise parents planning to use a restraint at discharge:

a. To bring the car carrier's instructions with them, if not already glued to seat;

b. To plan an extra 20 minutes for review of the car carrier's instructions and harness adjustments;

c. To plan for a set of lap belts to be available for the car carrier and a set for everyone else who will be riding in the vehicle;

d. To bring 2 receiving blankets, 2 small towels, or 4 extra diapers for padding around the infant while in the car carrier; and

e. To bring a bath towel or small blanket to level the base of the car carrier when in the family vehicle.

4. Demonstrate proper use of the car carrier according to the manufacturer's instructions:

a. Harness Placement: Place harness over shoulders of unbundled baby while still in maternity ward. For warmth, bulky blankets can be placed on top of harnessed baby.

b. Harness Adjustment: Demonstrate correct threading of buckles to prevent slippage.

c. Placement in Vehicle: All infant car carrier's face the rear.

C. Hospital Pharmacies and Gift Shops Could: Stock popular infant car carriers and/or convertible car carriers that will serve newborns through children up to about 40 pounds. Crashworthy car carriers that do not require the use of top tether straps will suit a larger number of families than those that do.

D. Pediatricians, Family Practice Physicians and/or Their Office Personnel, Pediatric Nurse Practitioners and Public Health Nurses Could: 
1. Bring up and sell the idea of crashworthy car restraints to parents.

2. Hand out literature to those without restraints and to those with nonconvertible infant car carriers that necessitate the later purchase of a second, child-sized restraint.

3. Write on their prescription pad instructions to obtain and use an infant/child restraint on every car trip!

4. Follow up on the usage of crashworthy restraints by those who have them:

a. How did the child get to the health facility that day?

b. How consistently do the parents use the car child restraint?

c. Are the parents having any difficulties using the child restraint?

d. Have the parents demonstrate proper use of any harnesses. Check for correctness by consulting instructions glued to carrier or in a separate manual.

e. Visually or verbally ascertain how the parents secure the restraint in their vehicle with the vehicle's safety belts:

1) Which direction does the restraint face? [Infant car carriers face the rear. Child restraints face forward.]

2) How taut and how solidly anchored are any top or side tether straps? f. Ask parents at each future office visit about their continued use of crashworthy car restraints. [There tends to be a decrease in the use of restraints as infants approach toddlerhood.] When a convertible car carrier has been switched from its rear-facing infant position to a forward-facing child position, or when a second child-sized restraint has been purchased, have parents again demonstrate their knowledge of proper use of the car restraint.

5. Urge the use of one or more of the following crashworthy systems for children who have outgrown their car carriers or harnesses, and who weigh 40 pounds or more:

a. Auto lap belt plus 2-inch firm cushion underneath child to keep belt low across hips.

b. Auto lap belt plus 2-inch firm cushion and auto shoulder belt if it crosses child's chest but does not cross face or neck.

c. Auto lap and shoulder belts without cushion for taller child whose head would extend 3 inches or more above vehicle seat back if seated on a 2 -inch cushion.

6. Make available a recycling bulletin board in office waiting room for parental resale of used crashworthy child car restraints. 


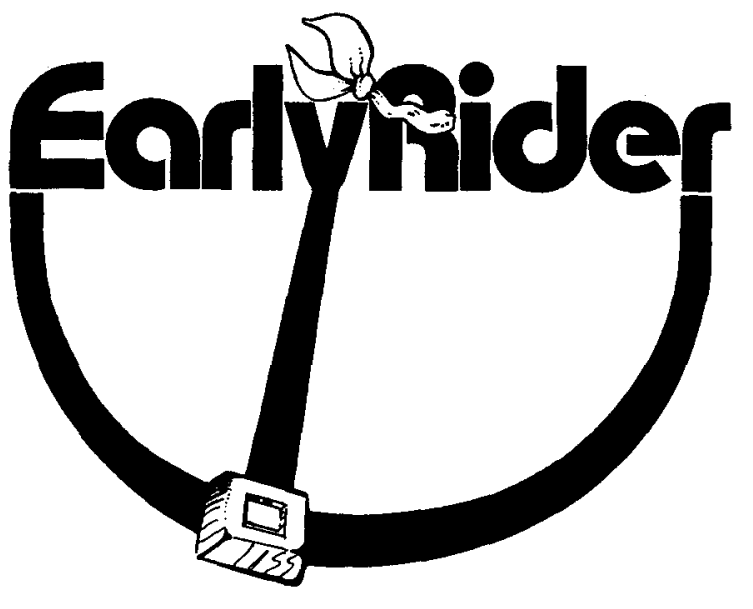

\section{LOAN A SEAT}

\section{How to Establish and Operate an Infant and Child Restraint Loan Program}

EarlyRider is produced by the National Highway Traffic Safety Administration in cooperation with Michigan's Motor Vehicle Occupant Protection Program, the Michigan Jaycee Auxiliary and Action for Child Transportation Safety. 
TABLE OF CONTENTS

1. Children are breakable

2. Why a restraint loan program?

3. How does it work?

4. Has anybody tried it?

5. How many people do we need? What must they do? 5

6. Space needed 5

7. Supplies and equipment 5

8. What restraints should we handle? $\quad 6$

9. How do we get the first group of restraints?

A. Donations of restraints

B. Buying restraints

10. 'What rental fee should we charge?

A. Infant restraints

B. Toddler restraints

11. Selling new restraints

A. Buying at wholesale

B. Setting a price

12. Sales and use tax

13. Helping others sell or swap 9

14. How can we attract parents?

A. Publicity

B. Community education activities

C. What if we have a long waiting list?

15. What is the usual procedure for loaning a seat?
A. Reservation
B. Pick-up
C. Demonstration of correct use
D. Safety education
E. Paperwork
F. Keeping the baby buckled-up

16. Liability

17. What about evaluation?

Appendix
A. Description of some typical programs
B. Shopping guide
C. List of manufacturers of child restraints
D. Application for retailer's license (sales tax)
E. Sample rental form
F. Sample return reminder letter
G. Sources of materials 


\section{Children are breakable}

In normal, everyday wear-and-tear, children hold up very nicely. But in a car that stops suddenly or crashes, many children don't do well at all.

Why? Because so many parents don't realize how dangerous the automobile is to young children. And they haven't done anything to protect their children.

Imagine a car traveling at just $\mathbf{3 0} \mathrm{mph}$. That's the speed the passengers are traveling too. Then there's a crash .... and the car stops. But the passengers keep moving at $\mathbf{3 0} \mathrm{mph}$ until they are stopped by something . . . with the force of a fall from a three-story building. That can be rough on anyone, especially a child.

The fact is, the most common causes of death and injury to children in automobile crashes are:

1. being thrown into the windshield, dash board, some other part of the car, or into another passenger;

2. being crushed by adults who are not wearing safety belts;

3. being thrown from the car.

Maybe you can understand how automobile crashes are the Number 1 killer of young children ... ahead of all other types of accidents and all diseases.

But there is an easy cure for this epidemic: child restraint devices and safety belts. They work in two important ways:

1. They anchor a child to the vehicle seat. If the car hits something, the restraint will help the child slow down with the car. This reduces the forces to which the child is subjected, because the car itself is absorbing much of the energy of the crash as its metal structure collapses. Without a belt or restraint device, a child would absorb the entire force of the crash when he or she hits the windshield or dash.

2. A safety belt or restraint device helps to spread the force of the crash over the strong bony structure of the body. Restraint devices used for children up to about four years old are better because they are designed to spread crash forces over a much larger body area than safety belts.

For children four years old or less involved in automobile crashes, safely constructed infant and child restraint devices can reduce the probability of death by more than 90 percent. The probability of serious injury can be reduced by up to 78 percent.

For children over four years of age, lap belts alone have been shown to reduce the probability of fatal injury by 81 percent and serious injury by 64 percent.

Unfortunately, less than 10 percent of our children are protected by child restraints, and many of these devices are inadequate or improperly used.

Besides people not knowing that restraints are important for their children, the main reasons for so few young children being protected are that parents feel they cannot afford a safe device, cannot decide what device to get, or don't know how to use properly the one they have.

A child restraint loan program can help solve all these problems.

This manual was developed to help service organizations and other groups establish effective child restraint loan programs. 


\section{Why a restraint loan program?}

No question about it: Safety belts and child restraints save lives. But the majority of people refuse to use them.

If adults won't even use safety belts already available in their cars, how can you get them to use child restraints they will have to buy?

The answer is simple: offer them a bargain. People who won't pay $\$ 20$ to $\$ 50$ to buy a child restraint are delighted to be able to rent one for a small service charge of, say, $\$ 6.00$.

Loan programs can be effective in several ways.

- First, they obviously provide immediate benefit for babies who ride in the borrowed seats.

- Then, when the infants become toddlers, many parents will want to buy a larger toddler restraint.

- Later, the "safety habit" created by child restraints will mean a higher percentage of children will be willing to use a safety belt.

- Other children in the family and parents may begin using their safety belts more frequently, especially if safety belt education is part of the loan program.

- Publicity about the program will help increase public awareness of the life-saving and injury-reducing benefits of safety restraints. Each seat loaned to a family will become a traveling advertisement for safety. As a consequence, many people may be motivated to buckle up their families in safety belts and child restraints.

\section{How does it work?}

Very simply, the sponsoring group obtains some infant restraints, publicizes their availability, and loans them out for a service charge and a deposit. In about nine months when the infant has outgrown the seat, the parents return it. and get their deposit back. Then, the sponsoring organization will loan them a toddler restraint or give them advice on where to buy a good one. Service charge funds are used to cover expenses, buy more restraints, or finance other projects of the organization.

\section{Has anybody tried it?}

Restraint loan programs are run by a variety of organizations, including service clubs, La Leche Leagues, childbirth education groups, day care centers, pediatric clinics, hospitals, hospital auxiliaries, health maintenance organizations, churches, safety organizations, and employers.

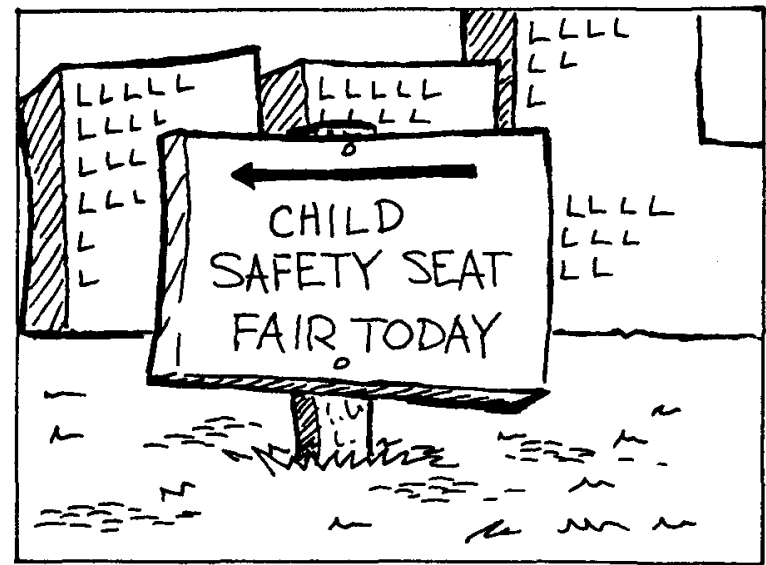

Some groups consider the program a public service and keep the service charge as low as possible just to cover costs. Other groups use the program as a fund-raiser to support additional activities.

The concept of a loan program seems to have been developed or at least implemented about the same time by two groups: the Coldwater Chapter of the Michigan Jaycee Auxiliary and the Seattle Chapter of Action for Child Transportation Safety. The Jaycee Auxiliary effort, however, generated more response.

Under the title "Buckle Up Babes," the concept was quickly adopted by the Michigan Jaycee Auxiliary as a state project. More than 70 auxiliaries there now have "Buckle Up Babes" programs. The National Jaycee Auxiliary also adopted it as a special project, thereby helping to spread it to auxiliary chapters in many states. Now, many other organizations have recognized the tremendous benefits of a restraint loan program and are helping to fill the growing public demand for affordable restraints.

See Appendix A for more information on some typical child restraint loan programs around the country. 


\section{How many people do we need? What must they do?}

From one to five people can handle this project, depending upon how ambitious it is. Most of the work is in getting started. Once underway only a few hours of effort per month are needed.

Assuming you organize into a committee structure, the basic assignments might break down in this way:

1. Chairperson

A. Direct all committee functions

B. Conduct all restraint rentals (This presumes spare restraints are kept by the chairperson; if restraints are stored elsewhere, others certainly could conduct rentals. See Chapter 15 for procedures for loaning a restraint.)

C. Obtain new restraints (Always mark each new seat with the name of your organization and an identification number. Use an engraving tool, if possible.)

2. Treasurer - Secretary (one or two people)

A. Maintain all records

1. File of rental agreement forms (permanent)

2. Two card files on restraints currently on loan

(a) one alphabetical file

(b) one file by date of expected return

3. Financial accounts

(a) rental and deposit fees

(b) sales taxes (if you are selling restraints)

B. Conduct correspondence

1. Letters or phone calls to customers

(a) when restraint is available

(b) when restraint is scheduled to be returned

2. Thank-you notes to organizations and businesses that help

3. Letters to community groups and individuals to promote the project

C. Pay bills

3. Publicity/education sub-committee

A. Obtain informational materials (See Appendix G)

B. Plan and set up displays; conduct workshops; make presentations; stage contests

C. Work with merchants

1. Sale of safe restraints
2. Increased advertising; better in store displays

D. Prepare newspaper articles and releases; plan and stage "media events"

E. Work with hospitals and health-care professionals

For more information on the subject of publicity and education, see Chapter 14 .

\section{Space needed}

No special office space or storage space is needed. Committee members can perform their tasks from their own homes or offices, and most restraints will be on loan at any given time. Extras stack easily on a few square feet of basement floor or unused office space. But if space is a problem, a church or community center might be willing to provide some storage space for a volunteer group.

\section{Supplies and equipment}

Very few materials are needed. They are:

1. A telephone for giving information and taking orders. This can be the private phone of a committee person.

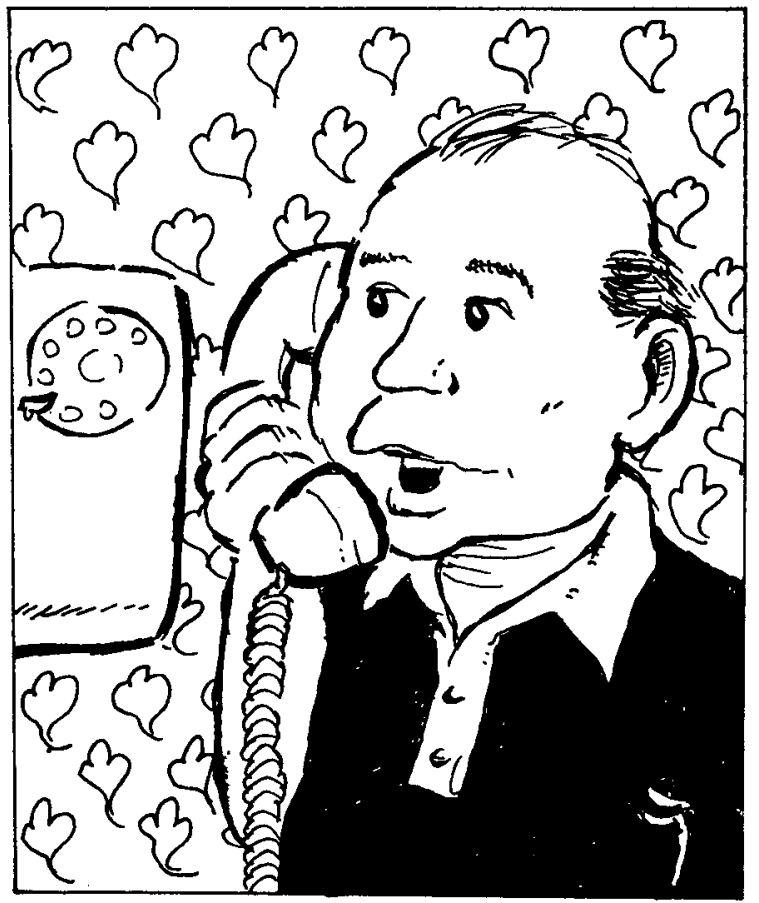

2. Rental contracts or agreement forms and instruction sheets for the use of the restraint devices. (You may be able to get these duplicated free or for just the cost of the paper. Check with schools, churches, insurance agents, local government, chambers of commerce.) 
3. A rubber stamp for your informational pamphlets which announces the loan program and gives a phone number.

4. Postage stamps, stationery and envelopes, notebook for record keeping.

5. Informational materials. Child Restraint Systems for Your Automobile is a comprehensive pamphlet which tells why child restraints are necessary, how to use them properly, and what to consider when selecting a model. An initial supply for community groups is available without charge from the NHTSA. Single copies are always free. Negatives are available so that groups that desire larger quantities can print their own. See Appendix G for more information.

6. Audio-visual Aids. Group presentations frequently can be more entertaining and effective if you have a film or filmstrip.

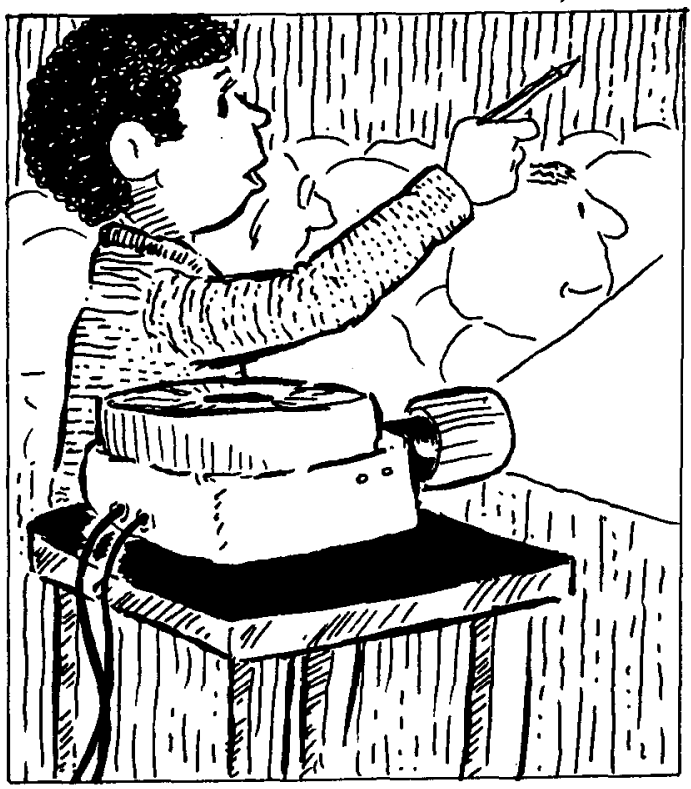

Your governor's highway safety representative may have a loan library. Check Appendix $\mathrm{G}$ for more sources.

7. Gummed labels for the bottom of each restraint seat. This would give the date by which it should be returned and two phone numbers that can be called to find out where to return it. (Some groups have discovered it is not a good idea to put a return address on the seat. That resulted in people leaving returned seats on doorsteps and porches with no phone contact to say who they were. If they have to call you, you can make a mutually convenient appointment.)

\section{What restraints should we handle?}

Your first decision should be whether you want to loan (a) infant seats, (b) convertible seats (for infants and toddlers), (c) restraints designed just for children one to four years old, or (d) a combination of these restraints.

Most groups prefer to loan just infant restraints. Since babies outgrow these devices within a year or less, a good rate of turnover is maintained. Another advantage is that all infant seats fit in all vehicles, and, if you must purchase your supply, the initial cost is relatively low.

Restraints designed for both infants and toddlers or those for just toddlers can present some problems for your project.

First, due to a wide range in size and different anchoring requirements, some devices either won't fit or cannot be anchored safely in certain vehicles. You'll need to have several models on hand to be certain of fitting the majority of vehicles.

Second, these devices are usually more expensive than infant restraints, so unless your supply is donated, your service charge and deposit will have to be higher than the charge for infant seats. Even if you are willing to loan a restraint for more than a year, parents may be reluctant to put that much money into a rental.

A very worthwhile alternative to consider is stocking two or three samples of several different convertible or toddler models as part of a onemonth "try-before-you-buy" rental. Many parents would greatly appreciate the opportunity to try different models to be certain of finally buying the one best suited to their needs.

Once you have decided upon the audience you will serve and the type or types of restraints you want to handle, you must select the models. The shings to consider are:

- Does it perform satisfactorily in a dynamic test? (See the EarlyRider Fact Book for an illustrated list of most of the safely constructed child restraint devices now on the market.)

- Is it likely that parents will use it correctly? (Some restraints require more buckling and anchoring than others. The EarlyRider Fact Book details the advantages and disadvantages of child restraints now on the market.)

- On which devices can you get the best deal? (The best deal is "free," of course, but not unless the free restraints are safe and likely 
to be used properly. The next section discusses some possibilities.)

- Finally, survey the major stores in your community and compile a listing of all the safely constructed restraints they are carrying and the current prices. You may discover that one or more convenient restraints are not available or are offered at unreasonable prices.

\section{How do we get the first group of restraints?}

Donations of restraints

The first and most desirable alternative to explore is the donation of safely constructed child restraints by one or more local retailers. If successful, you won't have to worry about finding money to buy your restraints, and you'll be doing local retailers a favor by getting them involved.

When you approach a retailer, point out these advantages:

- Loan programs tend to increase dramatically retail sales of child restraints in the community.

- Donated devices are a very inexpensive form of advertising. The retailer will receive favorable publicity when the program is announced in the media and every time a media event is staged to generate community interest in the use of restraints.

- Greater visibility for the retailer's brand(s) of child restraints should increase the demand for that particular brand, and the public will know where to buy.

Even if no retailer is interested in giving restraint devices without charge to get your program off the ground, don't give up on this possibility. When retailers see how much positive publicity is generated, they may be much more receptive to a later request for additional devices.

While local retailers are often willing to make donations to loan programs, the manufacturers are usually not willing and it would probably be a waste of time to contact them.

\section{Buying restraints}

If you can't get a supply of restraints free, then you'll have to find some money to buy what you need. Consider these alternatives:

- Solicit donations from area service clubs, businesses, safety councils, unions, insurance agencies, etc. You might ask each to donate the price of one or two restraints.
- Take out a loan. A loan under $\$ 500.00$ can be put on VISA, Mastercharge or other cards, perhaps, at an 18 percent annual interest rate. Since you eventually are going to earn much more than 18 percent on your investment, this can be a fiscally responsible way to start. A two- or three-year regular bank loan may be possible. (Enough rental fees to pay off your investment easily can be collected in two years or less.)

- Borrow the funds from your organization's treasury.

Once you have adequate funding for your program, you'll want to look for the best buy you can get on child restraints.

First, try to buy at wholesale prices directly from the manufacturer. Generally, this requires buying in lots of eight or twelve. Appendix $\mathrm{C}$ gives you the names and addresses of the manufacturers of safe restraints and the minimum orders they may be willing to handle.

If you can't buy at wholesale, your second option is to seek a discount from a local retailer. Remind the retailer of the significant publicity benefits that will result from his or her cooperation.

A third possibility would be to buy a limited number of second-hand restraints. Ads in the local papers should bring responses from many families with children who have outgrown their restraints.

If you must pay full retail price for all of your restraints, shop carefully. Prices vary greatly from one store to another even on the same restraint device.

Finally, don't forget to pay the sales tax on any restraints your group purchases, if required.

\section{What rental fee should we charge?}

\section{Infant Restraints}

Among the groups surveyed, the service charges range from $\$ 5$ to $\$ 8$ for a nine to twelve month period. What you charge will depend on your source of funding, expenses, and whether or not you want to make a profit. For shorter loan periods, the charges can be reduced. Deposit charges range from $\$ 3$ to $\$ 10$, and seem to depend on the perceived risk of damage or non-return. The programs surveyed, however, report very few problems with seats damaged or not returned. One program charges no deposit.

\section{Toddler Restraints}

Because toddler restraints can be used for up to 
three or four years and purchased for as little as $\$ 25$ to $\$ 30$, some parents will consider it to be cheaper and less aggravation to buy a restraint than rent one. So the approach taken by most programs which handle toddler seats is to offer a one

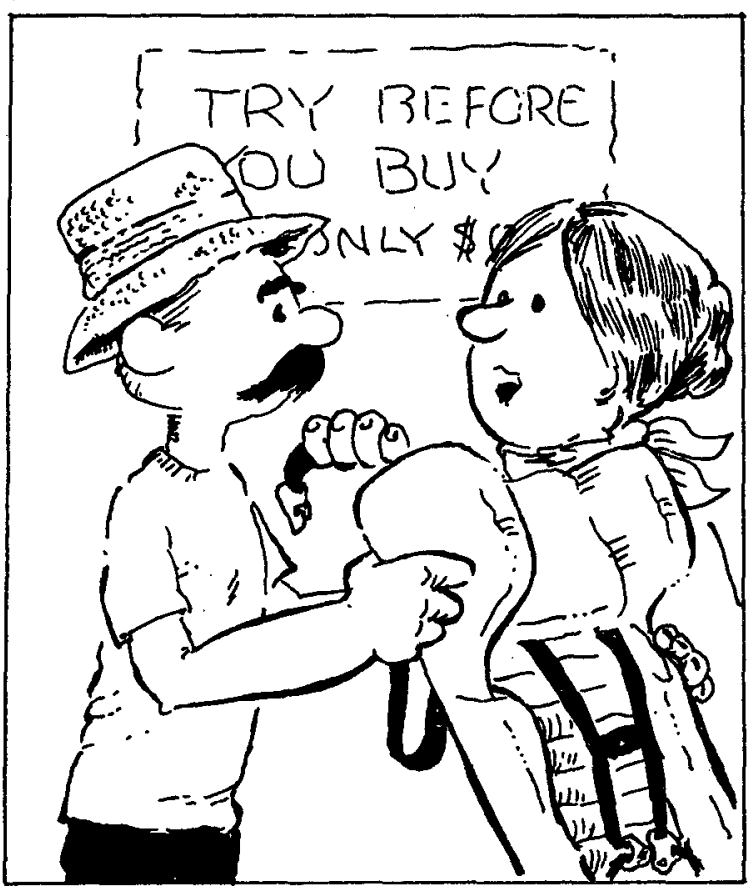

month "try-before-you-buy" loan for toddler seats. There usually is a service charge of one or two dollars, plus a deposit of $\$ 3.00$ to $\$ 10.00$.

With so many models on the market, the opportunity to try out several different models can be a great help to a family deciding upon the seat which will best serve their needs.

Only a few programs offer long-term rentals for toddler restraints, but these groups report that they are surprised by how many parents want this service. For one year, the service charge runs from $\$ 5.00$ to $\$ 14.00$ and deposits from $\$ 5.00$ to $\$ 13.00$.

Whether or not you decide to handle toddler restraints, you should provide all customers with information on where to buy safe devices, which ones might be most suitable, and what they can expect to pay. The Shopping Guide (Appendix B) can be a useful handout.

\section{Selling new restraints}

Whether or not you decide to rent infant or child restraints, you might also consider selling restraints. A direct sale offers the advantage of a very quick return of your investment and an immediate profit (if that is your objective) to use to purchase more seats for rental or sale or for other group activities.

\section{Buying At Wholesale}

Several companies have indicated an interest in selling their restraints in small lots at wholesale prices to community service organizations. Many others may be willing if you approach them with a specific proposal. See the list of manufacturers in Appendix $\mathrm{C}$ for details.

\section{Setting a Price}

There is no easy guide to setting a good price, but there are several important things to consider. You may want to charge a little less than local stores to give people an extra incentive to buy a restraint. Can you sell it at your wholesale cost? Yes, but it might not be a good idea. Legally, no one can dictate your selling price, but if you conspicuously undersell a large, established local retailer and hurt their business, there may be trouble. The retailer may stop carrying the product, and this would cut off an important source of supply for many parents and hurt the cause of safety. Moreover, the company might refuse to sell you any more restraints, and the next community group that wants to work with that company may be turned down.

The solution? One group decided to offer a restraint that was not available anywhere else in the community. Another group decided to undersell the lowest priced local retailer by just a few dollars; since they did no media advertising, this caused no problems.

Keep in mind that some of your local retailers may not care if you greatly undersell them and they may even offer to supply you. You will have to study your local situation carefully before you set a price.

\section{Sales and use tax}

Most states require that a sales or use tax be paid on any transferred goods.

If your organization plans to rent restraint devices, the best advice is to pay the state sales tax when you purchase your restraints. (Non-profit groups normally don't pay sales tax, but only if the items are for their exclusive use.) Should your group be given any restraints without charge by a merchant, that merchant will have to remit to the state the sales tax.

If your group or the merchant pays the state sales tax, you don't have to worry about collecting and remitting to the state a "use" tax when you rent the restraint devices.

Should you decide to sell restraint devices, 
however, you must collect and remit to the state its sales tax. Before you begin, write to the Department of Treasury in your state and ask for a "retailer's license" application and information on how you must collect and remit sales tax. Be sure to get all regulations that apply to your activity and comply with them. (See Appendix D for an example of a typical "retailer's license" application.)

\section{Helping others sell or swap}

No matter what your involvement in renting or selling restraints, your program can serve as a "clearinghouse" for families who wish to buy or sell used child restraints (but only those that perform satisfactorily in a dynamic test). There are also many people who don't like the brand they have and would like to trade with someone else. You can help bring all these people together.

There are several ways to accomplish this. If you have a bulletin or newsletter, of fer to run little want ads. Set aside a few minutes of every meeting as a time for sales or swaps by members or guests. Also consider sponsoring a yearly or semi-annual garage sale of used baby equipment, including child restraints.

Don't forget to take advantage of every opportunity to distribute safety restraint information.

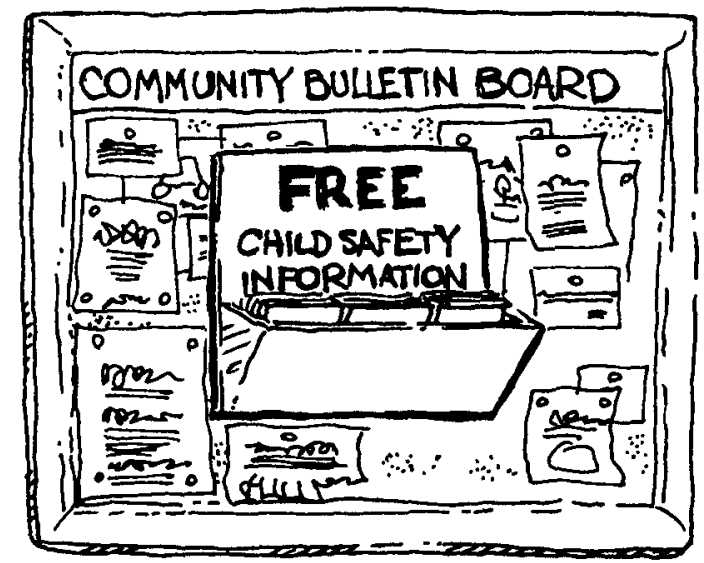

\section{How can we attract parents?}

If you are an employer, a day care center operator, or a member of an organization that already of fers services to parents of babies, then you may need very little advertising. (But you might want to do it anyway for its safety education value.)

Many groups have successfully used various combinations of publicity and education activities.

\section{Publicity}

The local media always are looking for good stories, especially those with "human interest." What your group will be doing can make the best copy of all. You just have to learn how to stage an event for maximum impact and how to help the media recognize its news value. The EarlyRider Publicity Handbook will give you excellent advice on working with the media.

Basically, you want to establish personal contact with your local newspaper editor and radio/tv news directors. Give them a brief rundown on what your group will be doing. Ask them for any advice on how best to give them what they want when you have something newsworthy. For example, they may need notification a certain number of days before an event to be able to schedule a reporter or camera crew. Or, they may want written material in a special format.

In any event, the EarlyRider Publicity Handbook will help you prepare a short, concise news release. Make certain this gets to the media several days before the event. Then call the editor or news director and bring the story to his or her attention. Point out any photo opportunities that might be possible.

Some newsworthy angles for restraint loan programs are:

- conducting an "observed use" study on child restraints in your community

- launching the program

- loaning the first seat

- a baby leaving the hospital in your seat

- speaking to a community group

- recognition of sponsors who made donations (news photos are very appropriate here)

- addition of new services

- safety tips before busy holiday weekends

- contests or raffles with a free loan as a prize

- meeting a goal for donations or growth

- interview with a local physician on importance of restraints

- local accident in which a child was safe in a restraint (ask local police to let you know of any such accidents they investigate)

- community safety displays

Other possibilities include articles or ads in newsletters or bulletins of various organizations. For example, some groups find that local diaper services will give them excellent publicity in their newsletters. 


\section{Community Educational Activities}

1. Distribute child restraint and safety belt pamphlets, handouts, and posters to maternity wards, health clinics, insurance offices, day care centers, nursery schools, doctors' offices, pre-natal classes and driver education classes. Encourage educators and health-care professionals to stress the importance of children and adults always being restrained. Tell them of all the printed and audio-visual material available for their use.

2. Be willing to give safety talks to groups of expectant or new parents and parents of young children. Especially good possibilities are pre-natal classes, nursery school parent groups, and women's organizations. The discussion guide and quiz in the EarlyRider Publicity Handbook outlines a ready-made presentation.

3. Create safety displays for shop windows, health fairs, and other community events. Encourage media coverage.

4. Urge merchants to remove from their shelves any restraint devices which do not perform satisfactorily in dynanic tests. Most merchants are unaware of the problem and are grateful for the information. Offer them copies of the Shopping Guide (Appendix B) for display or distribution. Also encourage merchants to give greater visibility to their restraint display, to separate the safe car restraints from the "in home" carriers, and to initiate sales and p omotional/informational activities.

5. Suggest to banks, credit unions, savings and loan associations, etc., that they o.fer child restraints as prizes for new investors. They also should consider restraint loan prograrns for members.

6. Find out what the "buckle-up" policy is at your child's preprimary, primary, or secondary school. At an absolute minimum, all school children should be required to use the safety belts provided in the vehicle in which they ride, and there should be only one person for each safety belt. While large school buses don't yet have safety belts, passenger cars and van-sized vehicles used frequently for field trips are so equipped. Also consider urging the use of child restraint devices for young children in day care and nursery schools.

Your governor's highway safety representative or local safety council may be able to tell you of others in your community who are interested in safety restraint education so you can all work together. Some restraint loan programs go far

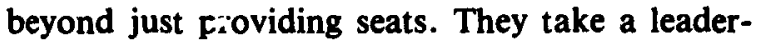
ship role in providing safety education for the whole community. Of course, you do not have to get involved with safety education, but it is a nice service to provide for your community if your organization can manage it.

\section{What if We Have a Long Waiting List?}

Some groups have found themselves with waiting lists of 10 to 20 or even 100 families. Most groups give priority to those who apply first. Some groups give special consideration to families who can't afford to buy a seat, or who may not be motivated to buy a seat if unable to borrow one.

For parents who have to purchase their own because no loan seats are available, you might offer to buy the seat from them at $1 / 2$ or $2 / 3$ the price when their baby outgrows it.

In programs where there are long waiting lists, you have to think hard about your goals. If loaning out all the seats is the primary goal, then the program has achieved maximum success. If the primary goal is getting all the babies in your community buckled up, then continue your education activities and try to expand your program or encourage other organizations in your community to establish their own loan programs. When other groups want to duplicate what you have done, be proud that you have made a contribution to your community worthy of imitation, and take pride in your leadership role.

\section{What is the usual procedure for loaning a seat?}

\section{Reservation}

Most programs encourage parents to make a reservation before the baby is born, sometimes with a deposit to insure that a seat will be available. Other programs have enough inventory to fill orders without reservations.

Tell parents that when they come to pick up the seat, you would like to spend 10 or 15 minutes with them to be sure they und rrstand how it should be used. Otherwise, many tend to leave the engine running, be impatient, and not really hear all that you want them to know.

Pick-up

Some programs encourage parents to pick up 
the seat several weeks before the baby is born. This is to insure that correct use can be demonstrated to the mother who will probably be the main person to use it. You can tell parents the loan period "starts" when the baby leaves the hospital. If the seat is picked up by daddy or grandma before baby comes home from the hospital, the demonstration of correct use may have less value. If the seat is picked up several weeks after the baby is born, then the baby has been riding unrestrained . . . a situation to be avoided.

\section{Demonstration of Correct Use}

- Using the baby (a doll, teddy bear, or, in a pinch, a bed pillow) show parents how to harness the baby into the seat and explain why it is necessary. Give parents a copy of manufacturer's instruction even if they are permanently attached to the seat. Show them how to put a rolled up blanket around a newborn's head and shoulders.

- Let parents repeat the demonstration for you so you will know they understand.

- In the parents' car, show them how to install the restraint with the vehicle lap belt. Discuss where in the car the baby should ride, how to position the vehicle seat head restraint, how to level the infant restraint, and how to attach the top anchor strap on those toddler seats that have one. Stress that the infant always rides backwards, and that everything must be buckled.

- Let parents demonstrate it to you.

The EarlyRider Fact Book describes the advantages, and proper use of all safely constructed restraints.

\section{Safety Education}

Explain to the parents right at the beginning why child restraints are necessary ... not just for the infant but for the toddler and pre-schooler as well. This all is covered in the safety pamphlet you will be giving them, but they need to hear it from you, too. When parents are being asked to change well-established behavior patterns, they may have to hear the safety message many times from many sources before it really has much effect.

Next, be certain to stress the importance of everyone in the vehicle using safety restraints. It really does not make much sense for parents to buckle-up a child and then not wear safety belts themselves. In a sudden swerve, the driver could be thrown away from the wheel and lose control of the car, causing a crash. Then, an unrestrained adult could be thrown into the child and cause serious injury to both of them. On top of that, it can be very hard to get a toddler to stay in his or her restraint if mommy and daddy don't want to be in theirs.

Finally, give the parents the Shopping Guide listing all the safely constructed child restraints on the market; tell them where they can be bought locally and at what prices. Stress that it is very important for them to select and have on hand a restraint to fit their child when he or she outgrows the infant seat. Offer to help them in deciding which one will be best for them when they are getting ready to buy. (Appendix B is a sample shopping guide with a price list that you may want to copy.)

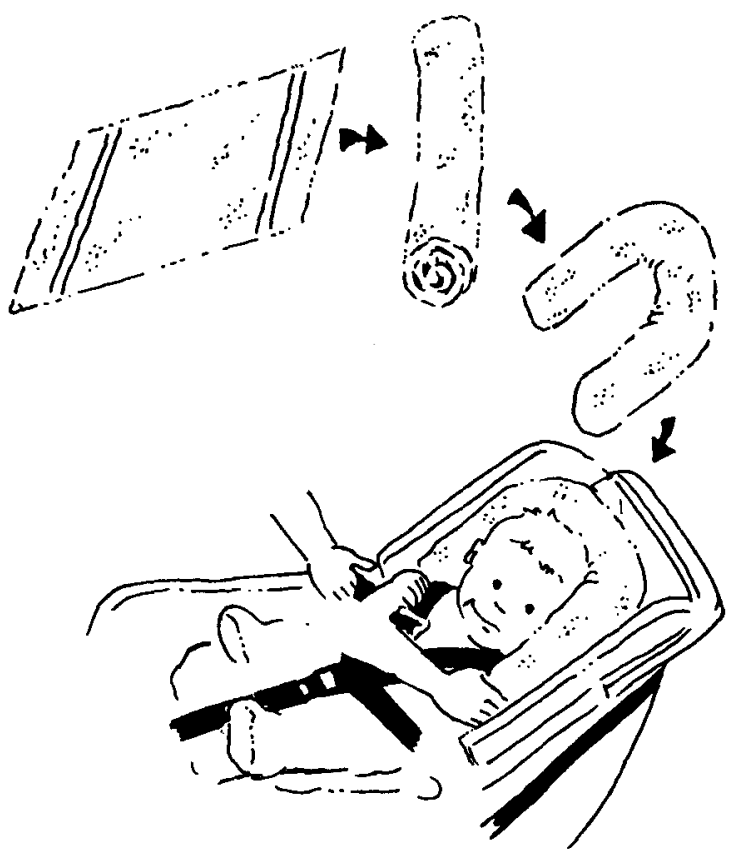

\section{Paperwork}

Before leaving with the restraint device, the parents should sign duplicate copies of a rental agreement which contains a prominent waiver of responsibility and clearly states the conditions of the rental. (See sample agreement in Appendix E.) Give them one copy, and keep another for your files.

Finally, collect the deposit and service charge and enter it on your ledger.

Now, congratulate yourself for having started another baby on a lifetime habit of safety. 


\section{Keeping the Baby Buckled-Up}

Getting the baby into your infant seat is a terrific start. But you want to keep the baby buckled-up after the rental seat is outgrown.

When it is almost time for the rental seat to be returned, you'll want to send a reminder letter or make a phone call. This is a very good opportunity to emphasize again the importance of having a toddler restraint before the infant seat is returned. (See the sample reminder letter in Appendix F.) Enclose another copy of your child restraint price list.

When the parents return the seat, ask if they have a safe restraint for their child. Offer them help in installing or properly using the device. (The shocking fact is that three-quarters of all child restraints in use are not used correctly, so the children are still not safe.) Consider walking out to the car to double-check for proper installation.

For those people who may have forgotten, who may not feel they can afford to buy a restraint, or who just haven't made up their minds, consider having on hand several different brands of restraints for older children. (Some restraints can not be used safely in some vehicles.) You can offer these on a short and inexpensive "try-before-youbuy" rental plan. Or, you might even consider a longer-term rental. The important point is, however, that no child has his or her seat turned in without having another seat to replace it immediately.

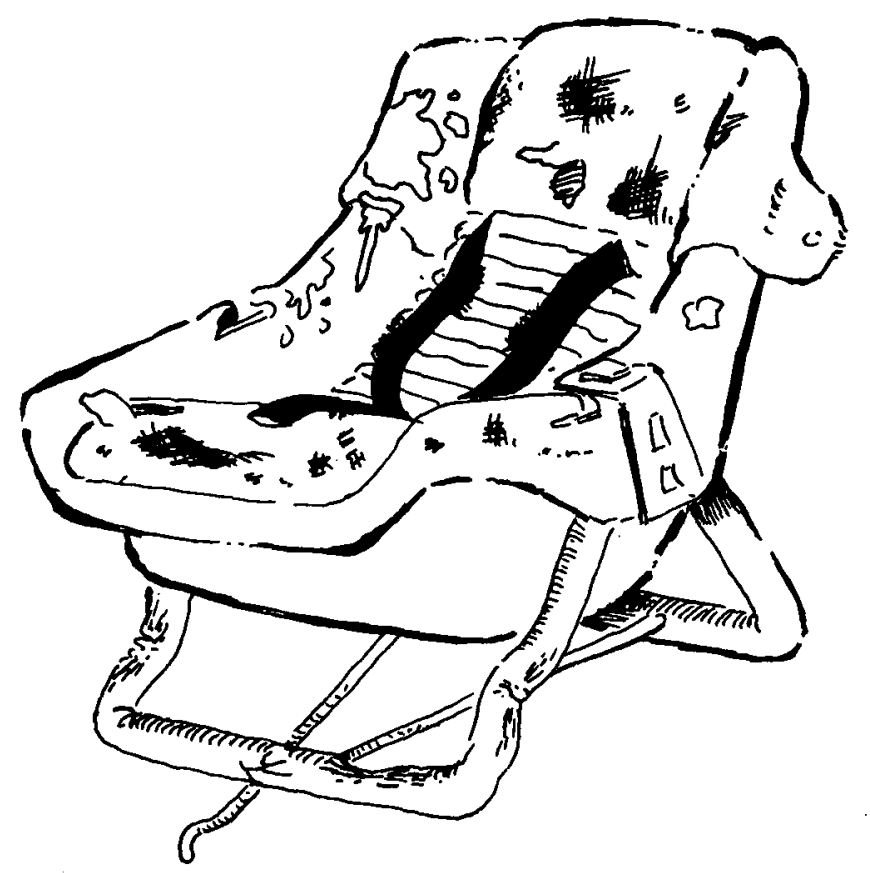

\section{Recycling the Seats}

Before you rent the restraint to another parent you should be sure it is in good condition.

The first thing you will want to know is if the seat was involved in an accident. You can be fairly certain that parents will tell you how well their child was protected, if they were involved in a crash.

Any seat that has been involved in an accident should be retired to a place of honor. In some cases the manufacturer will want you to return the seat to them and they will replace it for you.

If the seat was not involved in an accident, several things need to be examined before the restraint is ready to be rented again.

- Is the harness torn at any spot?

If so, the belt system should be replaced. This can easily be done on most restraints with replacements you can get from the manufacturers.

- Is the energy absorption padding torn? If so, it should be replaced with new padding from the manufacturer.

- Is there a metal frame? Does the frame rattle?

If so, you can tighten the screws. If the frame is still loose, do not reuse the seat.

- Are the bars twisted or bent?

If so do not use the seat! If you are not going to reuse the seat, destroy it so that it cannot be reused by someone else since full protection can no longer be guaranteed.

- Is the seat clean?

You will also want to be sure the seat is clean before another child uses it. Some programs retain part of the deposit fee for seats that are not clean when they are returned.

\section{Liability}

Many organizations express concern about the extent to which they might be held liable for damages should a child be injured while riding in a restraint they rented or sold. This is an important concern and should not be ignored. 
The consensus of the restraint manufacturers and the lawyers who have been consulted is as follows:

1. If the injury resulted from the failure of the restraint itself, then the manufacturer would be liable. In fact, to relieve retailers and wholesalers (such as community groups) of even the possibility of liability, most manufacturers will list by name on their insurance policy those who handle their product.

2. If the injury resulted from the failure of the restraint because a critical part was not provided by the retailer, wholesaler, or rental program, then there could be shared liability.

3. If the injury resulted from misuse of the restraint due to incorrect advice or demonstration given at the time of sale or rental, and if the manufacturer's instructions were not provided, there could be shared liability.

Even though there is no general knowledge of a liability award being levied against a community group involved in renting or selling restraints, there are several sensible precautions to take.

First, incorporate as a non-profit corporation. Individual members will then not be responsible for debts or judgments against the group.

Second, ask the manufacturer(s) of the restraints you want to handle to state to you in a letter the extent of their product liability coverage and the protection extended to your group.

Third, make certain that the people who rent or sell the restraints thoroughly understand the manufacturer's instructions on anchoring and use and can explain and demonstrate those instructions clearly. Provide each customer with a set of the printed instructions.

Fourth, before selling a new restraint, be certain all the parts and instructions are included. This is even more important when renting restraints.

Finally, should one of your rental restraints protect a child in a serious crash, retire it to a place of honor. The forces of a severe impact may seriously weaken parts of a restraint device, so there is no profit in taking a chance.

\section{What about evaluation?}

Being able to show how much impact your program has had can encourage your group and be a help for publicity, fund raising, and program revi- sion. Your evaluation also can help state and national safety and child care organizations with policy-making and program planning.

Here are some suggested activities:

- Before you officially start your program, make an informal observed use study to determine what percentage of children in your community ride buckled up. Observe cars with child passengers at several busy locations, such as the parking lots of shopping centers, recreation areas or day care centers. Is each child restrained or not? If restrained, is the restraint device appropriate to the child's age and size? Is it used correctly with everything fastened? Is it a safe design?

This observation activity is very newsworthy and will provide added justification for your group's efforts.

After your program has been operational for a year or two, observe again at the same locations.

- You can survey parent borrowers before and after they use the loan seat. Are more members of their families buckling up more often?

- You can make a survey of restraint sales in local stores and auto dealerships, both before your program starts and after it has been in operation a year or two. Are they increasing?

- Keep track of how many presentations you make and how many new loan programs and informational programs start because of your efforts.

If you need advice on evaluating your program, contact your governor's highway safety representative or write EarlyRider, NHTSA, 400 7th St., S.W., Washington, D.C. 20590. NHTSA is interested in receiving any survey results, too. 


\section{Appendix A \\ "A Description of Some Typical Programs"}

\section{Michigan Jaycee Auxiliary "Buckle Up Babes"} Project. Contact:

Dolly Claes

376 Western Avenue

Coldwater, MI 49036

PH: (517) 278-5302

or

Michigan Jaycee Auxiliary

BUB

45951 Amesbury

Plymouth, MI 48170

Since the Coldwater Jaycees pioneered the project in 1974, it has spread to other states as well. Some groups have less than two dozen seats to loan. Other groups, by constantly reinvesting the service charge to buy new seats, have 400 or more seats in circulation and still have long waiting lists. Many groups report the projects just "break even" because the income is constantly reinvested to purchase more seats. Although a profit is not the prime consideration, a few groups report a profit now, while some others expect to have a profit eventually, once the growth phase is completed. Charges vary from group to group, but $\$ 6$ deposit and \$6 service charge is common. The largest programs in Michigan are in Kalamazoo, Grand Rapids, and Coldwater.

Iron County Buckle Up Baby Committee. Contact:

Jean Jewett, Michigan Office of Highway Safety Planning,

7150 Harris Drive, General Office Building, Lansing, MI 48913

Phone: (517) 373-2930, or 394-1488

When this project was organized in 1974, it was run by one person who was not part of any organization. Money for restraints and pamphlets came from local service clubs, insurance agents, the city council, and retailers who sold child restraints. Very informal observed use studies in this small Upper Peninsula community indicated a dramatic rise in child restraint use during the first year of the program-from 7 percent to 40 percent for children under 12 months.
The La Leche League now runs this program. With constant reinvestment of profits, the project now has $\mathbf{4 0}$ seats with plans to buy more. There is a modest profit to help support educational activities. The deposit is $\$ 3$ and the service charge is $\$ 7$.

When parents return the infant restraint, they may borrow a child restraint (free) for one month. Within that month, they may come back as often as they wish and trade their child restraint for a different type. At the end of the month, they know what type of restraint they want and they purchase it from a local store. The original deposit is held until all seats have been returned.

This is a very popular service. It helps ensure that parents purchase a child restraint and that they will be happy with their choice.

Group Health Medical Center. Contact:

Mary Meland, M.D., 8600 Nicolet Avenue,

South Bloomington, MN 55420

Phone: 612-884-1150

The pediatric clinic has 400 infant restraints to loan to members of their prepaid medical plan. The three-year-old program has been so successful that it has spread to six other health maintenance clinics in the Minneapolis-St. Paul area. The deposit is $\$ 10$ and the service charge is $\$ 5.00$.

Eagle Heights Apartments. Contact:

Cathy De Angelis, RN, MD,

Eagle Heights Student Apartments, University of Wisconsin, Madison, WI

A no-charge loan closet of infant restraints has been established for some of the married graduate students to help new parents get into the habit of buckling up baby while saving up to purchase their own restraint.

Romeo La Leche League. Contact:

Lisa Headley, 60390 Mojave Lane, Washington, MI 48094

This program has infant restraints for loan as a service to the women who come to their meetings to learn about breastfeeding. The small profit 
realized is used to buy books for their library. The deposit is $\$ 6$ and the service charge is $\$ 6$.

Lansing Area La Leche Leagues. Contact:

Joey Latterman, 4534 Ethel,

Okemos, MI 48864

Phone: (517)-349-3521

They rent infant restraints and sell convertible infant/toddler restraints at a discount to the general public. In one year, they have sold 32 convertible seats and increased their inventory of infant rental seats from 12 to 60 . The money needed to start the project was loaned by a member, and that loan is almost paid off.

Family Centered Parents, Inc. Contact:

Jay Mosebach,

348 Paper Mill Rd.,

Newark, DE 19703

Phone: (302)-738-4948

This childbirth education group sells seats rather than loans them and offers two different brands at a discount price. They make them available at all the local hospitals and at several other locations in the area. They offer to buy back used restraints at $2 / 3$ the original price and resell them for a few dollars profit. The project has brought them a yearly profit of about $\$ 1,000$. A large majority of the local babies leave the hospital in a safe infant restraint, they estimate. To generate sales in the hospital, this group made a video tape which is played for new mothers.

Nursery Guild of Lakes Region General Hospital. Contact:

Mrs. Grace Herbert

RFD 5, Hoyt Road

Laconia, NH 03246

This group gets infant restraints from a local auto dealer and sells them to parents at a discount price just over cost. They promise to buy each seat back for $1 / 2$ price if it is in good condition. Then they resell it at a reduced price with the same offer. In just over a year, the Guild has put 142 seats into circulation at a profit of $\$ 355$. They also estimate a $90 \%$ use level.

\section{St. Johns Episcopal Church. Contact: Beverly Keicher \\ 4107 Swede \\ Midland, MI 48640 \\ Phone: (517)-631-9455}

This program is run by the church circle that takes care of the nursery. Advertisement is by word of mouth. No deposit or agreement is required. Service charge is $75 ₫$ per month for a minimum of six months for both members and non-members of the church.

Affiliated Hospitals Center, Inc. Contact:

\section{Margaret Lang}

Officer of Community Health

721 Huntington Ave.

Boston, Mass 02115

Phone: (617)-732-5940

Affiliated Hospitals Center is a union of the three Harvard University teaching hospitals and two neighborhood health centers. Their "Buckle Up Your Babe" program, which has reached many other institutions as well, includes aggressive promotion of restraints via bulletin boards, brochures, radio, television, hospital publications, and presentations to parents. Underway only since mid-1978, this effort has generated a heavy demand on the infant restraint rental services of fered through the office of Community Health. Their fee is $\$ 6.00$ deposit and $\$ 6.00$ rental for up to one year.

Advocates for Child Safety. Contact:

Dr. Marvin Rosen

Permanente Clinic

2211 East Mill Plain Blvd.

Vancouver, Washington 98661

A loose coalition of health care institutions and community groups cooperates in making available infant and convertible restraints at low prices throughout the Vancouver-Portland area. Restraints are sold at cost through the Kaiser Permanente Health Plan pharmacies, and through the gift shops at Emanuel Hospital, Portland Adventist Hospital, St. Joseph's Community 
Hospital,Vancouver Memorial Hospital, and the University of Oregon Health Sciences Center. The local chapter of Action for Child Transportation Safety buys and sells safe car seats at cost, and the Clark County Childbirth Education Association rents about 30 infant carriers. Most institutions also are involved in prenatal and postnatal educational programs for parents.

Borgess Hospital Pediatric Preventive Medicine Program. Contact:

Jana Hletko or H. David Claus

Borgess Hospital

1521 Gull Road

Kalamazoo, Michigan 49001

Phone: (616)-383-7333

As one segment of an overall Pediatric Preventive Medicine Program, Borgess Hospital operates an Auto Safety Program. Part of this program is the rental of infant and toddler restraints. The slogan for the loan program is "Give $2 \mathbb{C}$ for your child's safety." The loan fee is correspondingly $2 \mathbb{}$ a day and there is a $\$ 5.00$ deposit. People may borrow the seats for any period of time. The program owns a variety of seats in order to be able to provide people with a restraint to meet their specific needs. Almost 300 restraints are now being rented.

Hospital presentations to new mothers provide background information on child restraint systems and proper seat belt usage. The Auto Safety Program also provides community education through presentations to children in school classrooms and presentations before parent and community groups. 


\section{Appendix B \\ "Shopping Guide"}

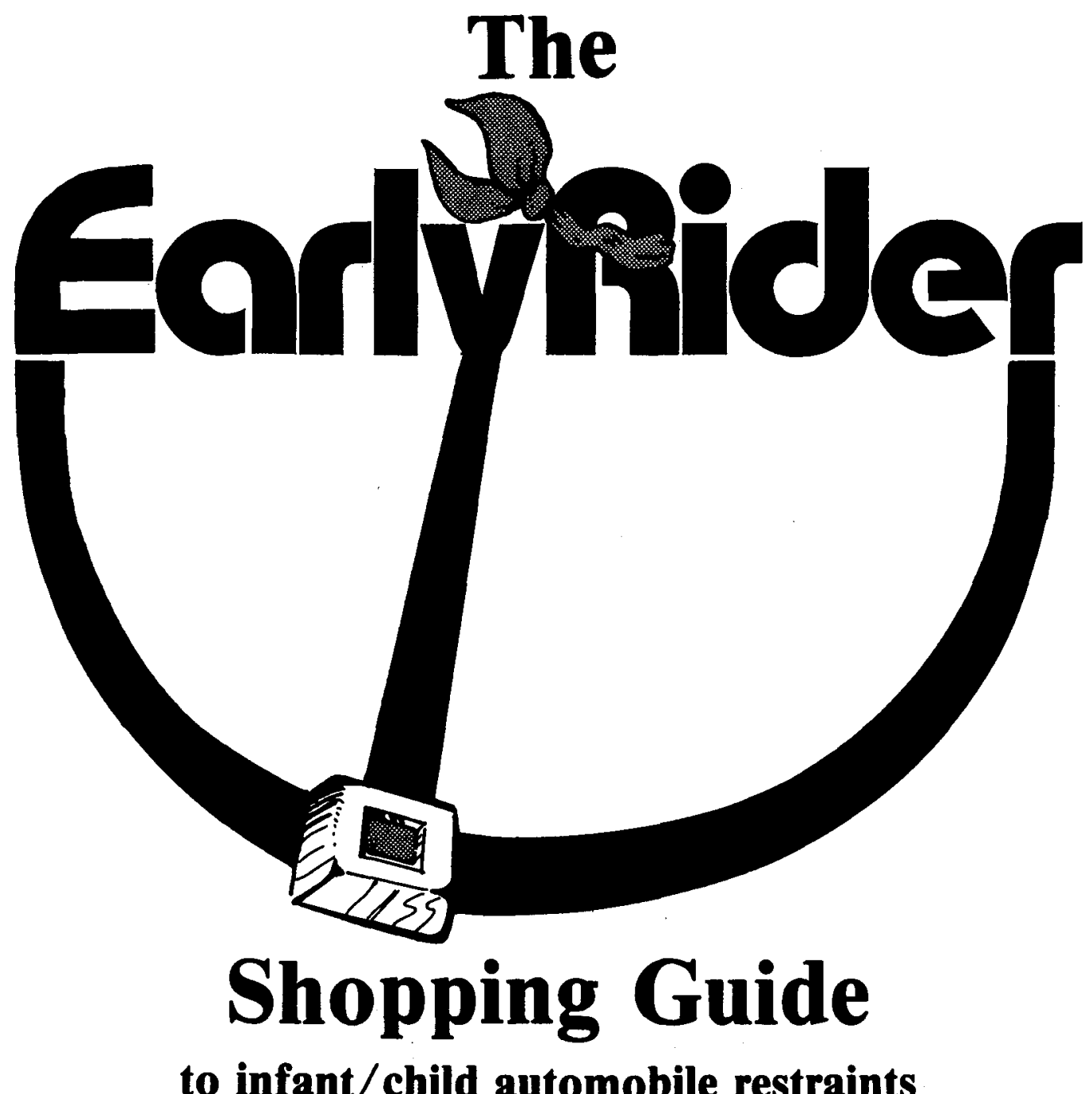

As of February, 1979, this is a complete listing of those infant and child restraints currently in production which have been determined to perform satisfactorily in dynamic tests (simulated crash tests). Satisfactory performance is defined as meeting or exceeding the critical elements of the National Highway Traffic Safety Administration's 1978 proposed revision to Federal Motor Vehicle Safety Standard 213.

There are three important considerations to keep in mind before selecting a restraint:

- The "best" restraint is the one in which your child will be most comfortable, that you can anchor properly in your car(s), and that you are willing to use every time you travel!

- If a restraint has a top anchor strap, it must be fastened to a special anchor plate installed in the rear or to a set of rear lap belts. It must be pulled tight. If you cannot or are not willing to do this, buy a restraint which is anchored only by a lap belt.

A side anchor strap fastens to the base of the nearest inboard set of auto lap belts. It keeps a restraint from tilting sideways in a swerve or crash. The use of this strap means better protection for a child.

- The same restraint may sell at a wide range of prices in a community. Shop carefully. The dealer prices will help you know how much of a bargain you are getting. Don't forget to check with service groups which may be renting or selling restraints. 
For Infants only (from birth to 20 pounds), $\$ 17$ to $\$ 24$ :

Dyn-O-Mite by Questor

Infant Love Seat by General Motors (Also sold as Ford Infant Carrier and Mopar Infant Safety Carrier)

Trav-L-Ette by Century

Convertible for Infants and Toddlers, $\$ 25$ to \$50:

T * Bobby-Mac Super by Collier-Keyworth

Bobby-Mac 2 in 1 by Collier-Keyworth

Bobby-Mac Deluxe by Collier-Keyworth

C B *

Sweetheart II by Bunny Bear

Kantwet Care Seat by Questor

Peterson Safety Shell by Cosco

Trav-L-Guard by Century

$\mathrm{T} * \quad$ Wee Care by Strolee

$T * \quad$ Safe N' Easy by Cosco

$T * \quad$ Peterson Safe-T-Seat by Cosco
For Toddlers only (from when they can sit alone until they weigh 40 or 50 pounds), $\$ 12$ to $\$ 50$ :

T / C B * Little Rider Harness by Rose Mfg.

$T$ * Child Love Seat by General Motors

T * Kantwet Fitz-All Deluxe by Questor Toddler Car Seat by Strolee

C B * Mopar Child Seat by Chrysler Corp.

C B * Tot Guard by Ford Motor Co.

T* These devices have a top strap which must be fastened and pulled tight or the device will be unsafe.

C B * It is best to use these devices in the center of the back seat.

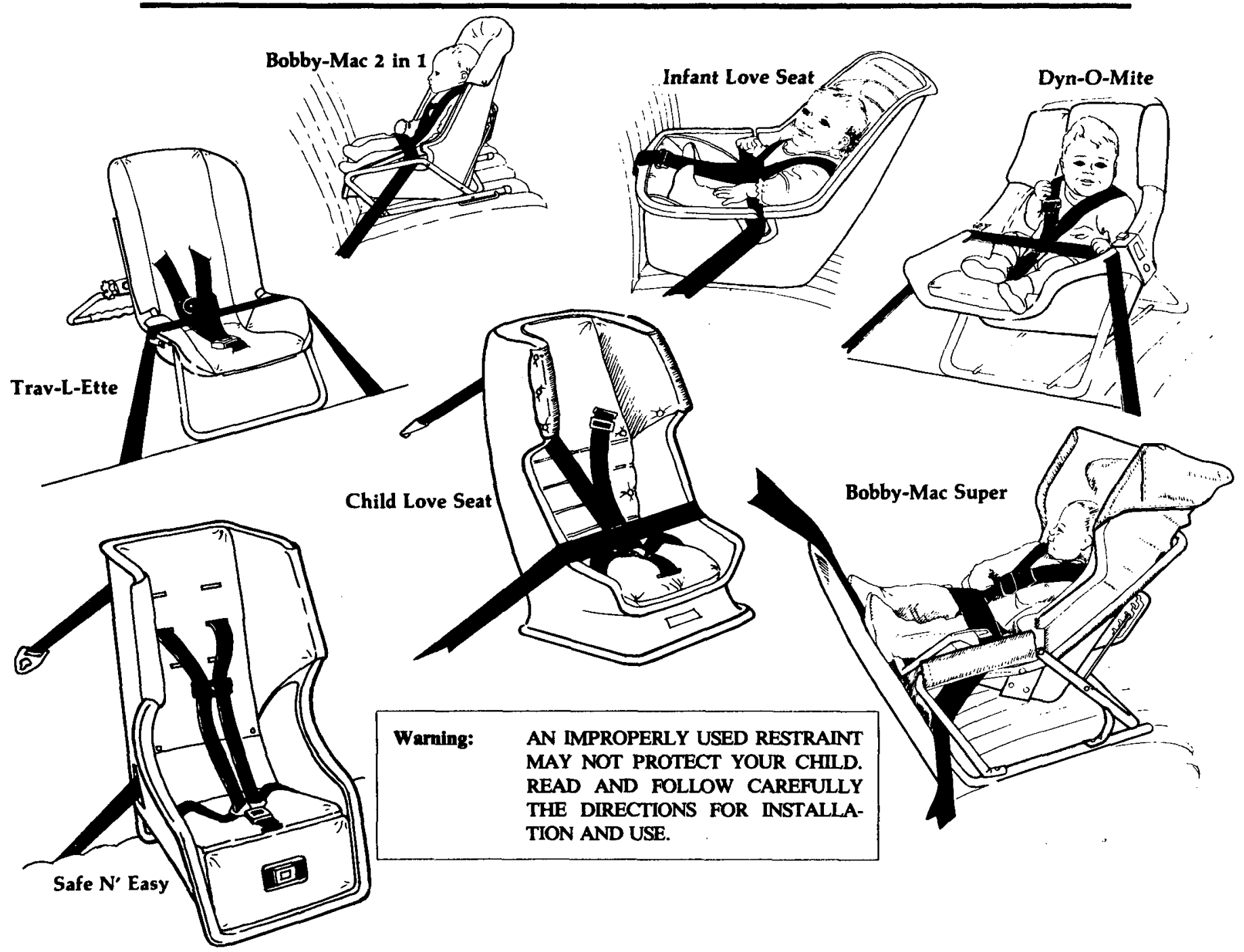




\author{
LOCAL CHILD RESTRAINT PRICE LIST \\ for \\ Buckleburg County and Vicinity
}

The Auxiliaries of Buckleburg Geneneral Hospital and its affiliate hospital in old Towne are working together to present an educational program promoting the use of safe car seats in vehicles carrying infants and older babies.

Holding your child on your lap while riding in a car does not provide enough protection, even if you're wearing a safety belt. The force generated in a crash multiplies your child's weight ten to twenty times, causing him to fly out of your armg and into the windshield or dashboard. old erauklduse a regular safety belt.

\begin{tabular}{|c|c|c|c|}
\hline STOREKOHALER & PRODUCT NAME & $P R L_{E}$ & COMMENTS \\
\hline $\begin{array}{l}\text { Abraham and Strauss } \\
\text { Zankers Shopping Center } \\
\text { Zankers, ST } \\
555-1400\end{array}$ & $\begin{array}{l}\text { Century } \\
\text { Peterson Safety Shell } \\
\text { Style \#74 (Child) } \\
\text { Strolee Infant Carrier }\end{array}$ & $\begin{array}{r}\$ 34.00 \\
29.99 \\
45.00\end{array}$ & \\
\hline $\begin{array}{l}\text { Bamberger's } \\
\text { Melto Park Shopping Center } \\
\text { Melto Park, ST } \\
555-4400\end{array}$ & $\begin{array}{l}\text { Kantwet Care Seat } \\
\text { Bobby Mac Super }\end{array}$ & $\begin{array}{l}35.00 \\
23.85\end{array}$ & $\begin{array}{l}\text { Also available at } \\
\text { same prices from } \\
\text { Brainwick Mall }\end{array}$ \\
\hline $\begin{array}{l}\text { Acme Bedding } \\
286 \text { Hobo Street } \\
\text { Buckleburg, ST } \\
555-2478\end{array}$ & Kantwet Care Seat & 24.95 & \\
\hline $\begin{array}{l}\text { Mechanik's Kids Stuff } \\
338 \text { Stateless Street } \\
\text { Buckleburg, ST } \\
555-1128\end{array}$ & $\begin{array}{l}\text { Seat (Infant) } \\
\text { Safety She } 11 \\
\text { Mac Super }\end{array}$ & $\begin{array}{l}19.95 \\
39.95 \\
34.00\end{array}$ & \\
\hline $\begin{array}{l}\text { Felucci's Sports Hotel } \\
24 \text { Hockshop Street } \\
\text { Cabaret, ST } \\
444-7930\end{array}$ & $\begin{array}{l}\text { Bobby Mac Deluxe } \\
\text { GM Love Seat (Child) }\end{array}$ & $\begin{array}{r}34.95 \\
44.50\end{array}$ & \\
\hline $\begin{array}{l}\text { Car City Automotive Parts } \\
\text { US Highway } 9 \\
\text { Fjord, ST } \\
333-8900\end{array}$ & $\begin{array}{l}\text { Century Trav-L-Guard } \\
\text { GM Love Seat (Infant) }\end{array}$ & & \\
\hline $\begin{array}{l}\text { Stern Department Store } \\
\text { Goodvalue Shopping Center } \\
\text { Guardian, ST } \\
222-7720\end{array}$ & $\begin{array}{l}\text { GM Love Seat (Infant) } \\
\text { GM Love Seat (Child) }\end{array}$ & $\begin{array}{l}26.50 \\
49.00\end{array}$ & \\
\hline
\end{tabular}




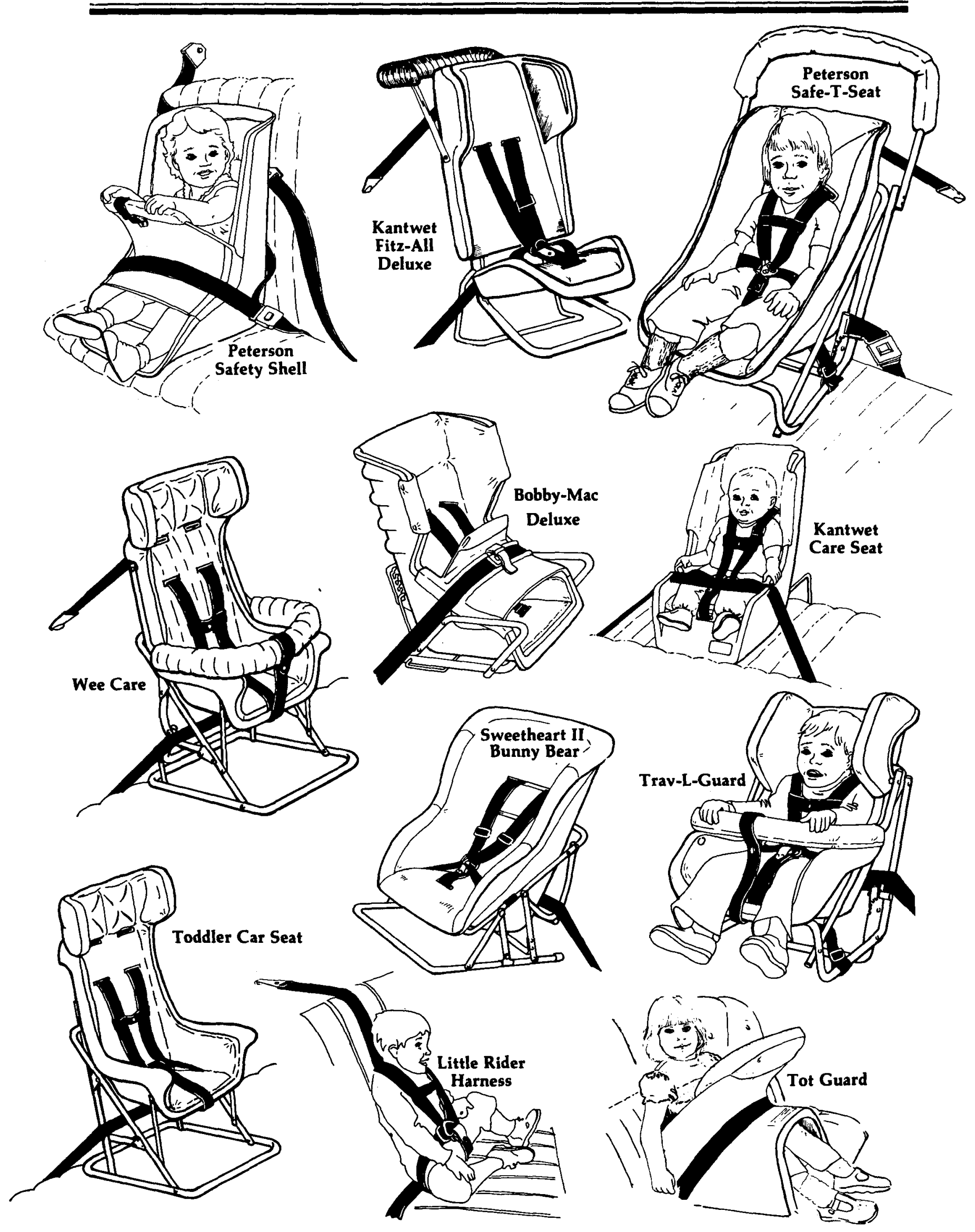




\section{Why use safety seats?}

In normal, every day wear-and-tear, children hold up very nicely. But in a car that stops or swerves suddenly or crashes, they don't do well at all. In fact, the automobile accident is the leading killer of young children . . . ahead of all other types of accidents and all diseases. Injuries from auto accidents also are a major cause of epilepsy and paraplegia.

Why? Because only an estimated 7 percent of young children are protected from injury in automobiles by the proper use of safely constructed child restraints or seat belts.

This "Shopping Guide" will help you understand why infant and child restraints are important. It also will help you in selecting the restraint best-suited for your child.

What can happen if infants or young children are not buckled up?

In a crash, a swerve, or a sudden stop. they can be thrown into the windshield, the dashboard, some other part of the car, or another passenger. They can easily be thrown out of the car.

Can't I protect my baby by holding it tightly in my arms?

The Highway Safety Research Institute at the University of Michigan studied this question. Male and female adult volunteers were anchored to a seat with lapshoulder belts. Each held a $17 \mathrm{lb}$. dummy to represent the average six-month old baby. In a series of tests simulating the effects of $15 \mathrm{mph}$ and $30 \mathrm{mph}$ impacts, not one volunteer could hold on to the "baby." Even knowing when the impact would occur and holding on with all their strength, the "baby" was torn from their arms.

Your arms usually are a very safe place for your infant, but not when riding in a car. Even a tiny $10 \mathrm{lb}$. infant will be thrown forward with a force of $300 \mathrm{lbs}$. in a $30 \mathrm{mph}$ impact. That's like falling from a three-story building.

\section{What does a restraint do?}

It holds the child in the car and safely spreads the forces of the crash over a wide body area. Safely constructed and properly anchored restraints have been shown to reduce the probability of a fatal injury in automobile crashes by $90 \%$.

\section{Which restraint is best?}

The best restraints are those which have performed satisfactorily in a dynamic test (a simulated crash test), and which are listed here. From among these, select the one in which your child will be most comfortable, that you can anchor properly in your car(s), and that you are willing to use every time.

What do I need for my infant?

Beginning with that first ride home from the hospital, all infants should ride in a semi-reclined, backward-facing restraint. It must be anchored to the vehicle seat by a lap belt. "Car beds" and household infant carriers are not designed to protect an infant in a car.

What do I need for my toddler or preschooler?

Children should ride in the infant position as long as they will tolerate it. But when they are big enough to sit up without help, they can safely be moved to a forward-facing seat or harness. As you can see from the list provided here, there are many safe models on the market. Before you buy, try in your car and with your child each seat in which you are interested. Make sure your child likes it and that you can anchor the restraint exactly as the manufacturer recommends. If one restraint seems too complicated or difficult to use, look for another model. No restraint will protect your child unless both of you are willing to use it properly and every time you travel.

Aren't safe restraints very expensive?

When you consider how important your child's health is to you, a safely constructed restraint is the best bargain you'll ever find . . . no matter what the price. Careful shoppers should be able to find the restraint they want at a price somewhere between $\$ 20$ and $\$ 40$. If that much money is a serious problem for you, see if any service organizations or hospitals in town are renting or selling restraints. Your cost usually will be much less.

What should I do when my child has to ride in a car without the restraint or finally outgrows it.

If a child restraint is not available, use a lap belt. This always is safer than riding unrestrained. Be certain the belt is as snug as possible and is positioned across the thighs/hip bones. A low, very firm cushion (such as a "boat cushion") can improve the fit. When your child outgrows the restraint, always require the use of the lap belt.

\section{Anything else I should know?}

- The restraint must be used exactly as recommended by the manufacturer or your child will not be as safe as possible.

- Never buckle two people of any size into one lap belt.

- Everyone in the car must buckle up. An unrestrained child or adult can be thrown into other passengers and cause very serious or even fatal injuries.

- Children will get used to any restraint if it is used on every ride. They also will be better behaved. 


\section{Appendix C \\ "List of Current Manufacturers of Child Restraints"}

Restraint
Bobby-Mac:
Two-In-One Car Seat,
Deluxe Car Seat,
Super Car Seat

Bunny Bear

Sweetheart II

Ford Tot Guard

G.M. Infant and

Child Love Seats

Kantwet Fitz-All

Deluxe,

Kantwet Care Seat,

Dyn-O-Mite

Little Rider Harness

Mopar Infant Safety

Carrier and

Child Shield

\section{Manufacturer}

Bobby-Mac Company

P.O. Box 209

Scarsdale, NY 10583

Attn: Quentin McDonald or

Collier-Keyworth

Company

P.O. Box 528

Gardner, MA 01440

Phone (617) 632-0120

Bunny Bear, Inc.

Nursery Lane

Everett, MA 02149

Ford Motor Company

Parts \& Service

29500 Plymouth Rd.

P.O. Box 3000

Livonia, MI 48151

General Motors Love Seats 400 Renaissance Center

Suite 1200

Detroit, MI 48243

Questor Juvenile

Furniture Co.

1801 Commerce Drive

Piqua, $\mathrm{OH} 45353$

Rose Manufacturing Co. 2775 S. Vallejo

Englewood, CO 80110

Chrysler Corporation

Mopar Seat

Parts Division

P.O. Box 1718

Detroit, MI 48288

or

\begin{abstract}
Sales Policy
Organizations needing quantities of restraints for their own use may order direct from either company. The Bobby-Mac Company will consider on an individual basis any request to sell its seats as a fund-raising project. Approval is not likely if the seats already are marketed in your community. No minimum order for dealer price.
\end{abstract}

Bunny Bear will sell at dealer prices to organizations needing seats for their own use. They will consider on an individual basis sales to community groups which want to rent or sell their product.

Ford will consider selling in quantity at dealer cost to organizations for their own use. Organizations wishing to sell or rent Tot-Guards must make arrangements with local Ford dealerships.

GM will sell at dealer cost in minimum orders of 12 units to organizations needing seats for their own use. Groups wishing to rent or sell their restraints must buy from local auto dealers or retailers.

Questor will sell to any organization in minimum orders of $\$ 125.00$.

Rose Manufacturing will sell to any organization. On first order, Rose will sell a minimum of 12 units at discount; subsequent orders must be for at least 72 units.

Chrysler will not sell direct to organizations. The Mopar Shield is available only through Chrysler, Plymouth, and Dodge dealerships. 
Restraint

Manufacturer

Donlee Plastics

2450 Finch Avenue, West

Weston, Ontario M9M

2E9

Safe-N-Easy,

Safe-N-Easy Recliner,

Peterson Safety Shells

Cosco Home Products

2525 State Street

Columbus, IN 47021

Strolee Wee Care Car Seat and Toddler Car Seat

Trav-L-Guard, Trav-L-Ette
Strolee of California 19067 S. Reyes Avenue Compton, CA 90221
Century Products, Inc. (eastern office) 2150 W. 114th Street Cleveland, $\mathrm{OH} 44102$ Phone: (216) 651-2000

(western office) 2020 E. 25th Street Los Angeles, CA 90058 Phone: (213) 235-4133
Sales Policy

Cosco will sell at dealer price to any organization needing restraints for its own use on orders exceeding $\$ 100.00$. Requests from organizations wishing to rent or sell Cosco products will be considered on an individual basis. However, Cosco will not allow an established retailer to be significantly undercut in price. (Cosco has purchased the Peterson Company. All inquiries concerning Peterson products should be directed to Cosco Home Products, attention Jim Foss.)

Strolee is willing to sell in minimum orders of 12 or more units at dealer price to any organization for its own use. The company will consider selling to groups which want to re-sell their product. However, they will not allow established retailers in a community to be un-, dercut significantly in price.

Century will sell at dealer price direct to any organization at a minimum order of eight units.

\section{RECENTLY DISCONTINUED PRODUCTS}

\author{
Restraint
American Safety Seat \\ Restraint
American Safety Seat \\ Manufacturer \\ Swyngomatic/Graco \\ Children's Products, Inc. \\ Main Street \\ Elverson, PA 19520 \\ Infantseat Harness \\ Questor Juvenile Furniture \\ Co. \\ 1801 Commerce Drive \\ Piqua, OH 45353
}


Restraint

Motor Toter

Posi-Test

Teddy Tot Astroseat V
Manufacturer

Century Products, Inc.

(eastern office)

2150 W. 114th Street

Cleveland, $\mathrm{OH} 44102$

Phone: (216) 651-2000

(western office)

2020 E. 25th Street

Los Angeles, CA 90058

Phone: (213) 235-4133

Hedstrom Company

P.O. Box 432

Bedford, PA 15522

International

Manufacturing Co.

2500 Washington Street

Roxbury, MA 12119 


\section{Appendix D \\ “Application for Retailer's License (Sales Tax)"}

Appendix D is a sample of the application for retailer's license in the state of Michigan. It is included here as an example of what may be required in other states. 


\section{MICHIGAN DEPARTMENT OF TREASURY APPLICATION FOR REGISTRATION}

This application is to be used in anplying for a Sales Tax License, or a Use Tax Registration, and to register for Income Tax Withholding, and for the Single Business Tax. All applicable portions of this application must be completed. It must include signature(s) of all owners of the business. It is essential that a new application be filed whenever there is a change in ownership, such as a change from one individual to another, a change in partners, an individual or partnership incorporating, etc.

For the convenience of the taxpayer, the Federal Employer Identification number assigned by the Internal Revenue Service will be used to identify accounts with the Michigan Department of Treasury. If you do not have a Federal Employer Identification number, but will have employees, application for this number may be filed with your Distriat Director of Internal Revenue. If you do not have a Federal Employer number at the time of registration, we will assign a Treasury number to you. When you are assigned a Federal Employer number, please include it on the next return filed with us. We will then discontinue the Treasury Number and use the Fcderal Employer rumber to identify your account.

\section{SALES TAX}

Any person who engages in the business of making sales at retail, of tangible personal property from locations in Michigan, will require a Sales Tax license. The license fee of $\$ 1.00$ made payable to the State of Michigan must accompany the application.

\section{USE TAX}

Any perscn having no retail location in Michigan, who intends to sell or lease tangible personal property to Michigan customers from an out-of-state location must secure a Use Tax registration. Persons in Michigan making purchases or rentals from an out-of-state source, or persons selling services of telephone, telegraph and other leased wire communications or transient hotel and motel room rentals must secure a Use Tax registration.

\section{INCOME TAX WITHHOLDING FROM EMPLOYEES}

Every employer required to withhold Federal Income Tax from compensation paid to an employee is required to withho!d Michigan Income Tax. An employee is an individual who performs services subject to the will and control of an employer both as to what shall be done and how it shall be done. For further clarification see Federal Employer's Tax Guide-Circular E.

\section{SINGLE BUSINESS TAX}

The Single Business Tax is effective January 1, 1976. The Single Business Tax is a type of added value tax which aiso includes elements of net income tax since the added value components of compensation, interest and depreciation are added to Federal taxable income to arrive at the Single Business Tax base.

The Single Business Tax is a specific tax on the adjusted tax base for every person with a business activity in this state which is allocated or apportioned to this state. A business activity whose gross receipts are less than $\$ 34,000$ is not required to file.

Taxpayers will include all business activities whether corporate or non-corporate lindividual, partnership, copartnership, cooperatives, joint venture, receiver, association, estate, trust or any other group or combination acting as a unit).

Parsons exempt from the imposition of this tax are persons who are exempt for Federal income Tax purposes except certain organizations who have taxable business income as part of their exempt activities.

Please be sure to answer all questions that apply to your business. Incomplete information may delay processing. After completion send to:

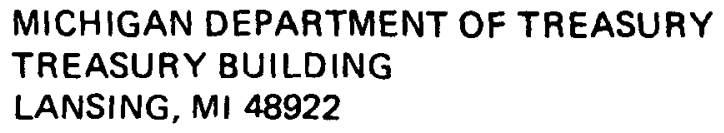

Phone: (517) 373-0888 


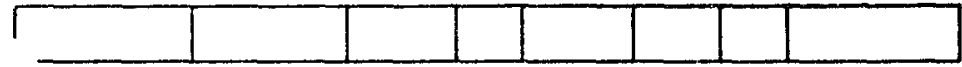

IIPDRTAYT Please read both Instructions and Application carefully. Type or Print legibly, and complete all applicable items. Incomplete information will delay processing of your application.

1. INDICATE TAXES FOR WHICH YOU WILL BE LIABLE, AND GIVE DATE THAT LIABILITY WILL BEGIN

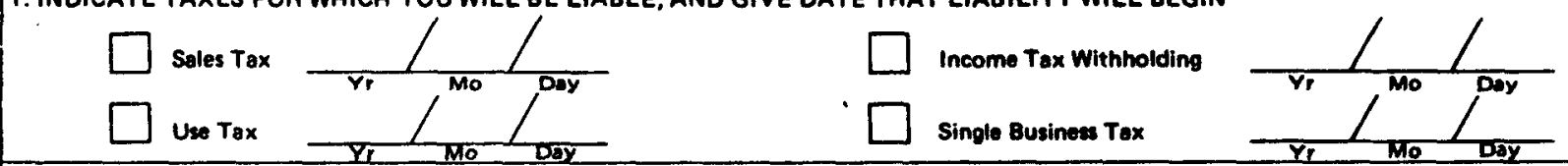

2. CORPORATION NAME/DIVISION NAME

3. LIST NAME(S) OF OWNER, ALL PARTNERS OR CORPORATE OFFICERS (Attech an additionsl list if neceseary)

\begin{tabular}{|c|c|c|}
\hline A. Neme (Last, First, Initial) & Titlo & Residence Phone No. \\
\hline Pesidence Address (street, city, state) & Social Security No. & Date of Birth \\
\hline B. Name (Last, First, Initial) & Title & Residance Phone No. \\
\hline Residence Address (street, city, state) & Socisl Security No. & Date of Birth \\
\hline C. Name (Last, First, Initial) & Title & Residence Phone No. \\
\hline Residence Address (street, city, state) & Social Security No. & Date of Birth \\
\hline
\end{tabular}

4. BUSINESS. TAADE OR ASSUMED NAME (if USEd)

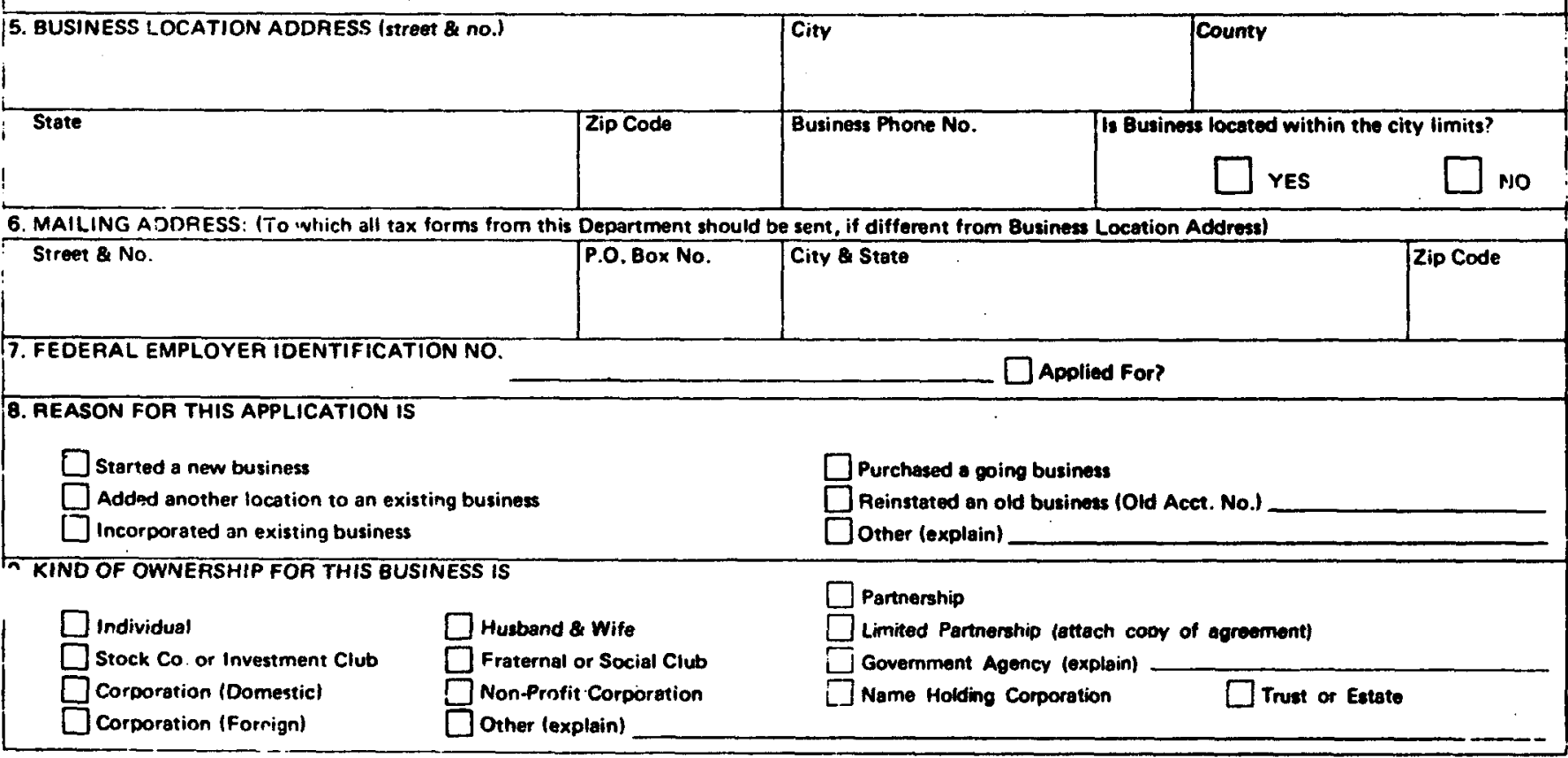




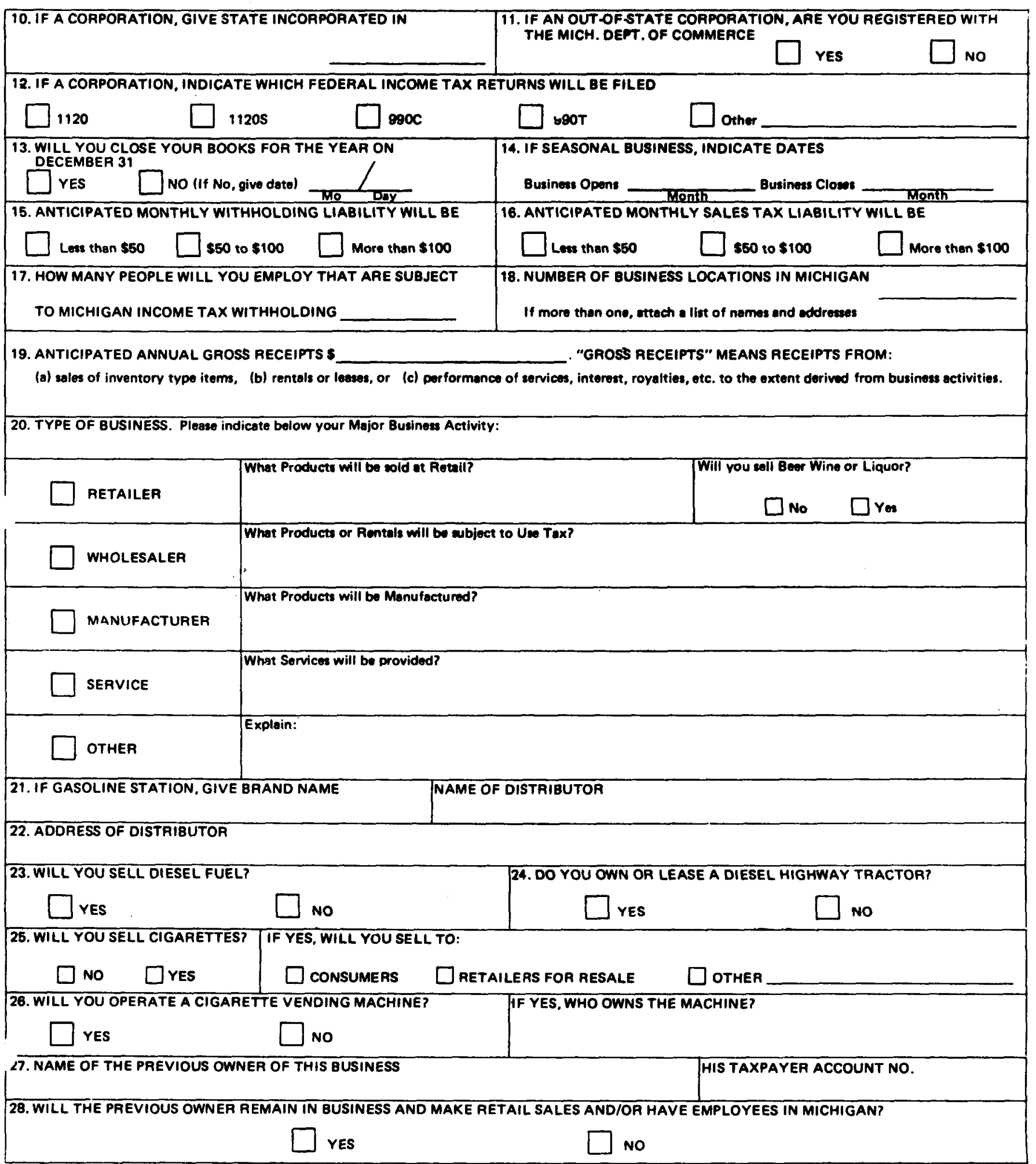




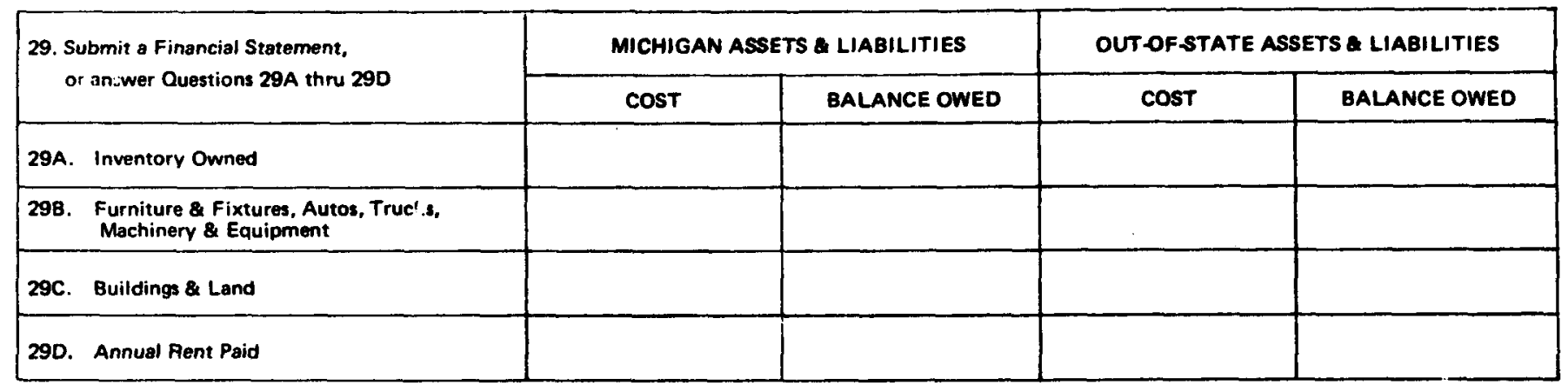

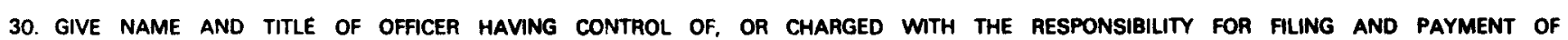
MICHIGAN TAX RETURNS

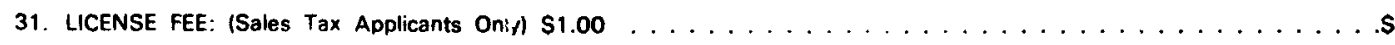

NOTE: A BOND MAY BE REQUIRED BEFORE A SALES TAX LICENSE IS ISSUEO

32. SIGNATURE OF OWNER - TWO (2) F \$RI INERS - TWO (2) CORPORATE OFFICERS - AUTHORIZED REPRESENTATIVE

I hereby declare, under pelıalty of perjury, that I have examined this application and the statements made and answers given are, to the best of my knowledge and belief, true and complete.

$\underline{x}$

Signature

Title

$\overline{\text { Date }}$

$\mathbf{x}$

Signature

Title

$\overline{\text { Date }}$

33. GIVE NAME AND ADDRESS OF PREPARER OF THIS FORM IF OTHER THAN TAXPAYER

NAME

PHCNE NUMBEA

ADDRESS 


\title{
Appendix E \\ "Sample Rental Form"
}

\author{
I \\ IRON COUNTY BUCKLE UP BABY COMMITTEE \\ CAR SEAT RENTAL AGREEMENT
}

FOR TODDLER SEATS

I HEREBY AGREE TO LEASE ONE CAR SEAT FOR A PERIOD NOT EXCEEDING FOUR WEEKS FOR A DEPOSIT OR FIVE DOLLARS. This includes three dollars security deposit and fifty cents per week rental fee. If the seat is returned clean, on time, and in good condition, THREE OF THE FIVE DOLLARS WILL BE REFUNDED. If the seat is dirty, late, or in poor condition, additional funds will be withheld. A late charge of fifty cents per week will be deducted from the refund for delinquent seats. If the seat is returned in less than four weeks. an additional refund of fifty cents per week will be made from the rental fee.

If the lessee has previously rented an infant carseat from the BUCKLE UP BABY COMMITTEE, the fifty cents per week rental fee will not be charged. Only the three dollar deposit will be required. The late charge of fifty cents per week will still apply.

If is expressly understood and agreed by the lessee that the rental service provided by the Buckle Up Baby Committee is done as a public service in the interest of safety and that the Buckle Up Baby Committee is not a dealer in this type of goods, and makes no warranty express or implied as to the fitness of said seat.

The undersigned further agrees to forever refrain from instituting, pressing, or in any way aid in claim, demand, action, or cause of action against the Iron County Buckle Up Baby Committee or any member thereof, for any damages, costs, loss of services, expenses or compensation for, on account of, or in any way growing out of, or which hereafter may grow out of the use of the said seat by lessee.

This agreement is binding on any heir, successors, or assigns.

Signature of lessee

Address
Date taken

Phone
Date due

$\$$

Amount paid 


\section{IRON COUNTY BUCKLE UP BABY COMMITTEE}

CAR SEAT RENTAL AGREEMENT

I HEREBY AGREE TO LEASE ONE G.M. INFANT LOVE SEAT FOR A PERIOD NOT EXCEEDING NINE MONTHS FOR A DEPOSIT OF TEN DOLLARS. If the seat is returned clean, on time, and in good condition, THREE OF THE TEN DOLLARS WILL BE REFUNDED. If the seat is dirty, in poor condition, or late, additional funds will be withheld. A late charge of ONE DOLLAR per month will be deducted from the refund for delinquent seats.

In case the period of use of the seat shall be more or less than nine months, the following provisions are understood and agreed:

If the period of use is from seven to nine months, there will be no change from the charges listed above.

If the period of use is less than seven months, an additional refund will be made at the rate of 75 c for each month less than seven.

If the baby has not outgrown the seat by nine months, the lessee may ask for a one or two month extension at no additional charge. This will be noted on the contract so no delinquent charge will be made.

If the baby has not outgrown the seat by eleven months, the lessee may ask to keep it for an additional month or two at the rate of $75 \mathrm{c}$ per month additional charge to be deducted from the refund. This will be noted on the contract so no delinquent charge will be made.

It is expressly understood and agreed by the lessee that the rental service provided by the Buckle Up Baby Committee is done as a public service in the interest of safety and that the Buckle Up Baby Committee is not a dealer in this type of goods, and makes no warranty express or implied as to the fitness of said seat.

The undersigned further agrees not to bring any claim against the Iron County Buckle Up Baby Committee, or any comnittee member, for any damages or expenses arising from use of the G.M. Infant Love Seat by lessee.

This agreement is binding upon any heir, successors, or assigns.

Signature of lessee

Address

Condition of seat noted:

$\overline{\text { Date taken }} \overline{\text { Date due }}$

Seat 非 


\title{
Appendix F \\ "Sample Return Reminder Letter"
}

\section{SAMPLE LETTER TO PARENTS REMINDING THEM TO RETURN THE SEAT}

Dear

Your infant restraint seat is due to be returned by If your baby has already outgrown it, we would appreciate having it back early because other babies are waiting for seats.

We hope you and your baby have enjoyed using the seat. You have done something very important for your baby by teaching him or her that we always ride buckled up.

Have you decided how you will buckle up your baby after you return the rental seat? Now that you have established a good safety habit, you don't want to spoil it by allowing your baby to ride unprotected, even for a week. Once babies get used to riding unrestrained, it can be very difficult to buckle them up later.

We (do, do not) (rent, sel1) forward-facing restraint devices for older children. (If you do offer restraints for toddlers, give details here.)

Enclosed is some information that might help you decide which child restraint would be best for you. If you have any questions, feel free to call me.

As a final word of caution, some restraints can't be safely used in some vehicles. A device may be too big for the vehicle seats or belts, or there may be no safe place to attach a top tether strap. Make certain the restraint will fit your vehicle and, if it has a top tether, that you have a place to attach it (such as a set of lap belts in the back seat or an anchor plate).

When you are ready to return the infant restraint, it would be a good idea to call me first to be sure $I$ will be home to refund your deposit.

\author{
Sincerely, \\ Jane Doe \\ (Telephone Number)
}




\section{Appendix G \\ "Sources of Materials"}

\section{GOVERNOR'S HIGHWAY SAFETY PROGRAM}

Each state has established a governor's highway safety program (GHSP) headed by a special representative of the governor. Each GHSP office is responsible for managing all highway safety programs in its state which are funded by state and federal money. Most GHSP offices distribute brochures, pamphlets, posters, films, and other audiovisual materials. Their staffs will work with people wanting to promote child passenger safety. The GHSP maintains statistics on highway safety and is an excellent source of information.

\author{
ALABAMA \\ Office of Highway and Traffic Safety \\ 2600 E. South Boulevard \\ Montgomery, Alabama 36116 \\ Phone: 205/832-5974
}

\section{ALASKA}

Alaska Highway Safety Planning Agency

Pouch N

Juneau, Alaska 99801

Phone: 907/465-4371

\section{ARIZONA}

Office of Highway Safety

1655 West Jackson Street

Phoenix, Arizona 85007

Phone: 602/261-7692

\section{ARKANSAS}

Coordinator of Public Safety

116 National Old Line Bldg.

Little Rock, Arkansas 72201

Phone: 501/371-1101

\section{CALIFORNIA}

Office of Traffic Safety

Business and Transportation Agency

P.O. Box 865

Sacramento, California 95804

Phone: 916/445-9718

\section{COLORADO}

Division of Highway Safety

4201 East Arkansas Avenue

Denver, Colorado 80222

Phone: 303/757-9381

\section{CONNECTICUT}

Department of Transportation

Bureau of Highways

24 Wolcott Hill Road

Wethersfield, Connecticut 06109

Phone: 203/566-4248

\section{DELAWARE}

Coordinator for Highway Safety

Treadway Towers

9 East Loockerman Street

Dover, Delaware 19901

Phone: 302/674-1738-302/678-4282

DISTRICT OF COLUMBIA

D.C. Office of Highway Safety

Presidential Building, Suite 604

415 12th St., N.W.

Washington, D.C. 20004

Phone: 202/347-7131

\section{FLORIDA}

Bureau of Highway Safety

Carlton Building-Room 530

Tallahassee, Florida 32304

Phone: 904/488-5455

\section{GEORGIA}

Office of Highway Safety

2175 Northlake Parkway

Building 4, Suite 144

Tucker, Georgia 30084

Phone: 404/393-7480

\section{HAWAII}

State Department of Transportation 79 South Nimitz Highway

Honolulu, Hawaii 96813

Phone: 808/548-5755

\section{IDAHO}

Highway Safety Section

Idaho Department of Transportation

Boise, Idaho 83707

Phone: 208/384-3533

\section{ILLINOIS}

Division of Transportation Safety

319 Administration Building

2300 South Dirksen Parkway

Springfield, Illinois 62764

Phone: 217/782-4972 


\section{INDIANA}

Dept. of Traffic Safety \&

Vehicle Inspection

215 North Senate Avenue

Indianapolis, Indiana 46204

Phone: 317/633-5870

\section{IOWA}

Office of Planning and Programming

Capitol Hill Annex

Des Moines, Iowa 50319

Phone: 515/281-3832

\section{KANSAS}

Safety Department of the Department of Transportation

10th Floor, State Office Bldg.

Topeka, Kansas 66612

Phone: 913/296-3551

\section{KENTUCKY}

Office of Highway Safety

Dept. of Transportation

State Office Bldg., Room 328

Frankfort, Kentucky 40601

Phone: 502/564-7074

\section{LOUISIANA}

Louisiana Highway Safety Commission P.O. Box 44061, Capitol Station

Baton Rouge, Louisiana 70804

Phone: 504/689-5460

\section{MAINE}

Director, Bureau of Safety

Transportation Building

Augusta, Maine 04333

Phone: 207/289-2551

\section{MARYLAND}

Division of Transportation Safety

Department of Transportation

P.O. Box 8755

Baltimore-Washington International Airport

Baltimore, Maryland 21240

Phone: 301/787-7157

\section{MASSACHUSETTS}

Governor's Highway Safety Bureau

50 Staniford Street

Boston, Massachusetts 02114

Phone: 617/727-5074

\section{MICHIGAN}

Office of Highway Safety Planning and State Safety Commission

7150 Harris Drive-General Office Bldg.

Lansing, Michigan 48913

Phone: 517/373-2930

\section{MINNESOTA}

Department of Public Safety

State Highway Building

St. Paul, Minnesota 55155

Phone: 612/296-6953

\section{MISSISSIPPI}

Governor's Highway Safety Program

510 George St., Suite 240

Jackson, Mississippi 39201

Phone: 601/354-6892

\section{MISSOURI}

Director of Highway Safety

2634 Industrial Drive

Jefferson City, Missouri $6 \mathbf{3 1 0 1}$

Phone: 314/634-2012

\section{MONTANA}

Highway Traffic Safety Division

Department of Community Affairs

Capitol Station

Helena, Montana 59601

Phone: 406/449-3412

\section{NEBRASKA}

Office of Highway Safety

Statehouse Station 94612

Lincoln, Nebraska 68509

Phone: 402/471-2515

\section{NEVADA}

Office of Traffic Safety

1923 North Carson

Suite 209-Capitol Complex

Carson City, Nevada 89710

Phone: 702/885-5720

\section{NEW HAMPSHIRE}

New Hampshire Highway Safety Agency

Pine Inn Plaza

117 Manchester St.

Concord, New Hampshire 03301

Phone: 603/271-2131

\section{NEW JERSEY}

Office of Highway Safety

State of New Jersey

4 Scotch Road

Trenton, New Jersey 08625

Phone: 609/292-3900

\section{NEW MEXICO}

Secretary of Transportation Dept.

P.E.R.A. Building-Room 220

P.O. Box 1028

Santa Fe, New Mexico 87501

Phone: 505/827-2045 


\section{NEW YORK}

Governor's Traffic Safety Committee

Empire State Plaza

Albany, New York 12228

Phone: $518 / 474-5777$ or 7283

NORTH CAROLINA

Governor's Highway Safety Program

Division of Motor Vehicles Annex

1100 New Bern Avenue

Raleigh, North Carolina 27611

Phone: 919/733-3083

\section{NORTH DAKOTA}

Traffic Safety Programs Division

North Dakota Hwy. Dept.

Capitol Grounds

Bismarck, North Dakota 58505

Phone: 701/224-2453

\section{OHIO}

Bureau of Transportation Safety

Department of Transportation

139 E. Gay St.

Columbus, Ohio 43215

Phone: 614/466-3250

\section{OKLAHOMA}

Oklahoma Highway Safety Office

Oklahoma Dept. of Transportation

2101 North Lincoln

Jim Thorpe Bldg., Room G-80

Oklahoma City, Oklahoma 73105

Phone: 405/521-3314

\section{OREGON}

Oregon Traffic Safety Commission

430 Summer St., N.E.

Salem, Oregon 97310

Phone: $503 / 378-3670$ or 3669

\section{PENNSYLVANIA}

Highway Safety Group

Pennsylvania Dept. of Transportation

Harrisburg, Pennsylvania 17120

Phone: 717/787-6855

\section{PUERTO RICO}

Traffic Safety Commission

P.O. Box 41289

Santurce, Puerto Rico 00940

Phone: $809 / 726-5290$ or 809/726-5150-Ext. 3550

\section{RHODE ISLAND}

Governor's Highway Safety Office

345 Harris Avenue

Providence, Rhode Island 02909

Phone: 401/277-3024

\section{SOUTH CAROLINA}

South Carolina Highway Safety Program Edgar A. Brown State Office Building

1205 Pendleton St., Room 477

Columbia, South Carolina 29201

Phone: 803/758-2237

\section{SOUTH DAKOTA}

Department of Public Safety

Diamond Oil Building

200 West Pleasant Drive

Pierre, South Dakota 57501

Phone: 605/773-3675

\section{TENNESSEE}

Highway Safety Planning Division

Office of Urban \& Federal Affairs

Suite 950, Capitol Hill Bldg.

301 Seventh Avenue, North

Nashville, Tennessee 37219

Phone: 615/741-2580

\section{TEXAS}

Texas Office of Traffic Safety

State Department of Highways and

Public Transportation

Austin, Texas 78701

Phone: 512/928-1170

UTAH

Dept. of Public Safety

455 East 4th South, \#314

Salt Lake City, Utah 84111

Phone: 801/533-5286

\section{VERMONT}

Highway Safety Program

Agency of Transportation

133 State St.

Montpelier, Vermont 05602

Phone: 802/828-2665

\section{VIRGINIA}

Department of Transportation Safety

300 Turner Road

Richmond, Virginia 23225

Phone: 804/276-9600

\section{WASHINGTON}

Washington Traffic Safety Commission

P.O. Box 1399

Olympia, Washington 98504

Phone: 206/753-6197 or 6538

\section{WEST VIRGINIA}

Governor's Highway Safety Representative

Governor's Office of Economic and

Community Development

Industrial Complex

Charleston, West Virginia 25305

Phone: 304/348-2234 


\section{WISCONSIN}

Division of Highway Safety Coordination

James Wilson Plaza-Suite 803

131 West Wilson Street

Madison, Wisconsin 53702

Phone: 608/266-0402

\section{WYOMING}

Governor's Office of Highway Safety

720 West 18th St.

Cheyenne, Wyoming 82002

Phone: 307/777-7497

\section{VIRGIN ISLANDS}

Virgin Island Office of Highway Safety

P.O. Box 1847

Fredricksted, St. Croix

Virgin Islands 00840

Phone: 809/772-3025 or 2946

\section{AMERICAN SAMOA}

Executive Office Building

Government of American Samoa

Office of Highway Safety

Pago Pago, American Samoa 96799

Phone: Int'l Oper. 688-9187

\section{GUAM}

Highway Safety Coordinator

Government of Guam

P.O. Box 2950

Agana, Guam 96910

Phone: (Thru Int'l. Operator) 646/5821, Ext. 60

\section{INDIAN TRIBES}

Highway Safety Program

Bureau of Indian Affairs

Division of Safety Management

P.O. Box 2186

Albuquerque, N.M. 87103

Phone: 905/568-1423

\section{NORTHERN MARIANA ISLANDS}

Acting Director of Public Safety

Office of the Governor

Commonwealth of the Northern Mariana Islands

Saipan, Northern Mariana Islands 96950

\section{OTHER SOURCES}

\section{National Safety Council}

The National Safety Council (444 North Michigan Avenue, Chicago, IL 60611) is a major national source of accident statistics. They also distribute a wide variety of materials useful for public information and education programs. They are now distributing "Childsafe," an in-hospital education program for new parents. This program is built around a slide show that explains the need for effective child restraint and how to use restraints properly. "Childsafe" is now in use in a large number of hospitals throughout the country.

Local safety councils

Many communities have local safety councils affiliated with the National Safety Council. They may be good sources for local information about child safety.

\section{State hospital associations}

Hospital associations actively support a variety of safety education programs through hospital auxiliary groups. Many have developed materials which have been adopted for use by community and civic groups.

\section{Action for Child Transportation Safety (ACTS)}

This is a national volunteer group which provides pamphlets, background information, and a member's newsletter on community child safety programs. Membership in ACTS is $\$ 5.00$. Send a self-addressed, stamped envelope for a list of information available to ACTS, Box 266, Bothell, WA 98011.

\section{Physicians for automotive safety (PAS)}

This professional organization distributes a variety of materials which can be used for patient education. They have sold over one million copies of their brochure, "Don't Risk Your Child's Life," and are now distributing an excellent 12-minute film with the same title. These materials are among the best for educating parents about the selection and proper use of child restraints. Write PAS, P.O. Box 208, Rye, NY 10580.

Film Loops, Inc.

Film Loops has produced a number of important educational programs and curriculum materials. Their filmstrip program, "Do You Care Enough" is designed for post-natal use in hospitals to convince parents to buy and use safe infant restraints. Other film and filmstrip programs focus on safety belt use by children and adults. Film Loops offers attractive prices for bulk orders. Write Film Loops, Inc., P.O. Box 2233, Princeton, N.J. 08540.

\section{Insurance Institute for Highway Safety}

This independent research organization has conducted a number of studies of child restraint use and effectiveness. The Institute distributes a film showing the dynamics of automobile crashes and how restraint systems protect young children. Write IIHS, Suite 300, 600 New Hampshire Ave., Washington, D.C. 20037. 
National Highway Traffic Safety Administration (NHTSA)

The NHTSA (US DOT NHTSA, 400 7th St., S.W., Washington, D.C. 20590) promotes child restraint usage through programs such as EarlyRider. It also distributes a series of publications on occupant restraints and loans films on many traffic safety topics. This agency also establishes safety standards for vehicle occupant protection including infant and child restraints. This is an excellent source for technical information on child restraints.

NHTSA maintains regional offices in ten cities. These offices work closely with state highway safety programs and respond to citizen requests.

Region 1: Connecticut, Maine, Massachusetts, Island New Hampshire, Vermont, Rhode

\section{NHTSA-Region 1}

Transportation Systems Center

Kendall Square-Code 903

Cambridge, MA 02142

Phone: 617/494-2680

Region 2: New York, New Jersey, Puerto Rico, Virgin Islands

NHTSA-Region 2

222 Manaroneck Ave., Suite 204

White Plains, NY 10605

Phone: 914/761-4250

Region 3: Delaware, District of Columbia, Maryland, Pennsylvania, Virginia, West Virginia

NHTSA-Region 3

793 Elkridge Landing Rd., Room D-203

Linthicum, MD 21090

Phone: 301/796-5117

Region 4: Alabama, Florida, Georgia, Kentucky, Mississippi, North Carolina, South Carolina, Tennessee

NHTSA-Region 4

Suite 501

1720 Peachtree Rd., NW

Atlanta, GA 30309

Phone: 404/881-4537

Region 5: Illinois, Indiana, Michigan, Minnesota, Ohio, Wisconsin

NHTSA-Region 5

Suite 214, Executive Plaza

1010 Dixie Highway

Chicago Heights, IL 60411

Phone: 312/756-1950
Region 6: Arkansas, Louisiana, New Mexico, Oklahoma, Texas

NHTSA-Region 6

819 Taylor St.

Fort Worth, TX 76102

Phone: 817/334-3653

Region 7: Iowa, Kansas, Missouri, Nebraska

NHTSA-Region 7

Box 19515

Kansas City, MO 64141

Phone: $816 / 926-7887$

Region 8: Colorado, Montana, North Dakota, South Dakota, Utah, Wyoming

NHTSA-Region 8

330 S. Garrison St.

Lakewood, CO 80226

Phone: 303/234-3253

Region 9: Arizona, California, Hawaii, Nevada, American Samoa, Guam, North Mariana Islands

NHTSA-Region 9

2 Embarcadero Center, Suite 610

San Francisco, CA 94111

Phone: 415/566-6415

Region 10: Alaska, Idaho, Oregon, Washington NHTSA-Region 10 3140 Federal Bldg.

915 Second Ave.

Seattle, WA 98174

Phone: 206/442-5935 